\title{
Segregation of Geniculocortical Afferents during the Critical Period: A Role for Subplate Neurons
}

\author{
Anirvan Ghosh and Carla J. Shatz \\ Department of Neurobiology, Stanford University School of Medicine, Stanford, California 94305
}

To investigate the cellular interactions within the mammalian visual cortex that are important in ocular dominance column formation, we have examined the role of subplate neurons in this process. LGN axons segregate in layer 4 of the cat's visual cortex between the third and sixth postnatal weeks to give rise to the adult pattern of ocular dominance columns. Subplate neurons are a transient population of neurons that sit in the white matter but have extensive projections into the overlying cortex, particularly layer 4, during neonatal life. Many subplate neurons are present at birth, but most are gone by the end of the period of LGN axon segregation. To examine whether these neurons are required for the segregation of LGN axons, we deleted them by intracortical injections of kainic acid either just after LGN axons had grown into layer 4 (first postnatal week) or later, just before the onset of segregation (third postnatal week). The consequences for the patterning of geniculocortical terminals were evaluated by transneuronal transport of ${ }^{3} \mathrm{H}$-proline injected into one eye at times when segregation would normally be complete. Following deletion of subplate neurons at either age, LGN axons failed to segregate into ocular dominance columns. Following the late deletions only, geniculocortical axons lost their laminar restriction to layer 4 and projected to layers 2 and 3 as well. Deletion of subplate neurons also resulted in long-term changes in the cytoarchitecture of layer 4.

These observations suggest that the interactions that mediate segregation of LGN axons within layer 4 of visual cortex are susceptible to influences from subplate neurons. Although the mechanisms by which subplate neurons exert their effect are not yet clear, these experiments strongly suggest that interactions between LGN axons and layer 4 neurons are not sufficient for column formation, and that subplate neurons most likely play a critical role in interactions leading to ocular segregation.

[Key words: subplate neurons, ocular dominance columns, visual system, geniculocortical axons, cortical plasticity, critical period]

\footnotetext{
Received July 27, 1993; revised Dec. 3, 1993; accepted Dec. 21, 1993.

We thank members of the Shatz Lab for help with surgeries and Drs. E. I. Knudsen, J. H. P. Skene, and W. T. Newsome for comments on the manuscript This work was supported by NIH Grant R37 EY02858 to C.J.S and a Bank of America-Giannini Foundation postdoctoral fellowship to A.G.

Correspondence should be addressed to Anirvan Ghosh, Department of Microbiology and Molecular Genetics, Harvard Medical School, 200 Longwood Avenue, D1-604, Boston, MA 02115.

aresent address: Division of Neurobiology, Department of Molecular and Cell Biology, LSA 221, University of California, Berkeley, CA 94720.

Copyright $(1994$ Society for Neuroscience $0270-6474 / 94 / 143862-19 \$ 05.00 / 0$
}

Visual experience can have a profound influence on the development of connections in the mammalian visual system. This phenomenon has been most thoroughly investigated with regard to the system of ocular dominance columns in primary visual cortex of cat and monkey (Hubel and Wiesel, 1977; LeVay et al., 1980). Axon terminals from neurons of the lateral geniculate nucleus (LGN), whose pattern of innervation of cortex gives rise to ocular dominance columns, are initially intermixed with regard to eye preference within layer 4 of visual cortex (Rakic, 1976; LeVay et al., 1978). Events mediated by neuronal activity and visual experience are known to be important in the formation of ocular dominance columns in layer 4 , since the final pattern of ocular dominance is susceptible to abnormal visual experience during postnatal development. For example, in the cat, closure of one eye before segregation of $\mathrm{LGN}$ axons results in a large shift in ocular dominance in favor of the open eye (Wicscl and Hubcl, 1963, 1965). Anatomical evidence indicates that axon terminals driven by the open eye expand to occupy a larger area within layer 4 , while there is a corresponding shrinkage of the area representing the closed eye (Shatz and Stryker, 1978; LeVay et al., 1980). Experiments that interfere directly with action potentials or synaptic transmission within cortex during postnatal development also prevent the anatomical segregation of LGN axons within layer 4 , suggesting that activity and synaptic transmission are necessary for LGN axons to segregate under normal circumstances (Stryker and Harris, 1986; Bear et al., 1990; reviewed in Shatz, 1990; Antonini and Stryker, 1993).

The factors that permit activity-dependent change in axon terminal arrangements are likely to have certain constraints, since the anatomical pattern of ocular dominance columns in layer 4 can be influenced by visual experience only during a restricted period in development - the critical period (Hubel and Wiesel, 1970; LeVay et al., 1980). A major question is, what changes occur in the visual cortex that promote axonal segregation and bring the critical period for layer 4 to a close? One striking cellular change in the cortex that begins just before and concludes just after LGN axon segregation is the disappearance of subplate neurons. These neurons sit directly below the cortical plate and are present in large numbers during fetal development (for reviews, see Shatz et al., 1991; Allendoerfer and Shatz, 1993). In the cat, subplate neurons begin to disappear due to cell death a few days before birth-shortly after LGN axons grow into layer 4 . Their numbers continue to decrease rapidly during the first month of neonatal life, until the end of the second postnatal month when most of them are gone (Valverde and Facal-Valverde, 1988; Chun and Shatz, 1989b). Subplate neurons are important for earlier steps in the development of LGN 
axons, and in fetal development apparently are required for LGN axons to select visual cortex as an appropriate cortical target (Ghosh et al., 1990; Ghosh and Shatz, 1993). During neonatal cortical development, subplate neurons can have extensive axonal projections into layer 4 (Friauf et al., 1990), and the neurons of layer 4 have a recurrent axon collateral within the subplate (Callaway and Katz, 1992), raising the possibility that subplate neurons may influence events taking place in cortical layer 4.

Here, we have investigated whether subplate neurons are involved in the process of ocular segregation of LGN axons in layer 4. LGN axons normally begin to segregate within layer 4 beginning around the third postnatal week, and segregated ocular dominance columns can be seen clearly by the end of the sixth week (LeVay et al., 1978). To examine the role of subplate neurons in segregation of the LGN axons, we deleted them by injecting small volumes of kainic acid into the white matter underlying visual cortex just prior to the onset of segregation and when they are still plentiful. At the end of the normal period of ocular segregation (6-8 weeks), we examined the pattern of ocular dominance columns in layer 4 of the subplate-ablated hemisphere by means of transneuronal transport of ${ }^{3} \mathrm{H}$-proline (Wiesel et al., 1974a; Shatz et al., 1977). We found that in the absence of subplate neurons the segregation of LGN axons into ocular dominance columns fails to take place. In addition, the deletion of subplate neurons alters the cytoarchitectural organization of visual cortex, particularly within cortical layer 4 .

\section{Materials and Methods}

Cortical injections of kainic acid were made in 26 cats between postnatal day 2 (P2) and P20, and the consequences examined between P14 and P100. The pattern of labeling of geniculocortical axon terminals was visualized by an intraocular injection of ${ }^{3} \mathrm{H}$-proline into the eye ipsilateral to the kainic injection 1 week prior to perfusion. The fate of layer 4 neurons in experimental animals was evaluated by labeling layer 4 cells in utero with an injection of ${ }^{3} \mathrm{H}$-thymidine at E39 or E40 and, subsequently, examining the distribution of the labeled cells in subplateablated animals. Several animals were also processed for histology and immunocytochemistry to evaluate the effects of the kainic acid lesions on the cytoarchitecture of visual cortex. The distribution of ages examined and the various analytical procedures are summarized in Table 1.

Kainic acid injections. Animals were initially anesthetized by inhalation of halothane $\left(3-4 \%\right.$ in $\left.\mathrm{O}_{2}\right)$ and maintained under halothane anesthesia $\left(1-2 \%\right.$ in $\left.\mathrm{O}_{2}\right)$ during surgery. The cranium was exposed by making a parasagittal incision over the scalp. A sterile dental drill was used to make a bone flap over visual cortex that could be lifted to reveal the dural surface. The neurotoxin kainic acid $(10 \mathrm{mg} / \mathrm{ml}$ in sterile saline; no. K0250; Sigma Chemical Co., St. Louis, MO) was injected into the white matter. [In most cases, the kainic acid solution injected included red or green thuorescent microspheres (Lumafluor Inc.) at a ratio of 9:1 (kainic acid:microspheres) to mark the injection site unambiguously.] Typically, two $0.5 \mu \mathrm{l}$ injections were made at the apex of the lateral gyrus, separated by about $1 \mathrm{~mm}$ in the anteroposterior dimension. Following injections, the bone flap was replaced, the skin overlying the cranium was sutured, and the kitten was revived from anesthesia.

Intraocular injections of ${ }^{3} \mathrm{H}$-proline. Animals were anesthetized as described above. The vitreous of one eye was injected with $2 \mathrm{mCi}$ of ${ }^{3} \mathrm{H}$-proline in $50 \mu \mathrm{l}$ of sterile saline $(0.9 \%)$ as previously described (LeVay et al., 1978) and the animal was revived from anesthesia.

Tissue preparation for histology. Postnatal animals were deeply anesthetized by an intraperitoneal injection of Nembutal $(35 \mathrm{mg} / \mathrm{kg})$. Animals were perfused transcardially using a peristaltic pump with cold 0.1 M sodium phosphate buffer followed by $4 \%$ paraformaldehyde in $0.1 \mathrm{M}$ sodium phosphate butter. Following perfusion, the cranium was removed and the brain stored in the same fixative at $4^{\circ} \mathrm{C}$. For histological analysis, horizontal sections were cut on a vibratome $(100 \mu \mathrm{m})$ or on a freezing microtome $(30 \mu \mathrm{m})$, and following immunohistochemical labeling (when appropriate) sections were mounted on gelatin-subbed
Table 1. Age distribution of kainic acid-treated animals and method of analysis

\begin{tabular}{|c|c|c|c|c|}
\hline $\begin{array}{l}\text { Num- } \\
\text { ber of } \\
\text { animals }\end{array}$ & $\begin{array}{l}\text { Age at } \\
\text { kainic acid } \\
\text { injection }\end{array}$ & $\begin{array}{l}\text { Age at } \\
\text { perfusion }\end{array}$ & $\begin{array}{l}\text { Immuno- } \\
\text { histo- } \\
\text { chemistry } \\
\text { (MAP2, } \\
\text { GFAP) }\end{array}$ & $\begin{array}{l}\text { Autoradi- } \\
\text { ography }\end{array}$ \\
\hline 1 & N/A & P44 & + & \\
\hline 1 & $\mathrm{P} 2$ & P10 & + & \\
\hline 1 & P3 & P16 & + & \\
\hline 2 & $\mathrm{P} 4$ & $\mathrm{P} 18$ & + & \\
\hline 1 & P5 & P29 & + & \\
\hline 1 & P9 & P31 & + & \\
\hline 1 & P7 & P14 & + & ${ }^{3} \mathrm{H}$-thy \\
\hline 1 & $\mathrm{P} 7$ & P19 & + & ${ }^{3} \mathrm{H}$-thy \\
\hline 1 & $\mathrm{P} 7$ & $\mathrm{P} 20$ & & ${ }^{3} \mathrm{H}$-thy \\
\hline 1 & $\mathbf{P} 2$ & $\mathrm{P} 70$ & & ${ }^{3} \mathrm{H}$-pro \\
\hline 2 & $\mathrm{P} 2$ & P55 & & ${ }^{3} \mathrm{H}$-pro \\
\hline 1 & $\mathrm{P} 2$ & P60 & & ${ }^{3} \mathrm{H}$-pro \\
\hline 2 & P3 & $\mathrm{P} 47$ & & ${ }^{3} \mathrm{H}$-pro \\
\hline 1 & $\mathrm{P} 4$ & P48 & & ${ }^{3} \mathrm{H}$-pro \\
\hline 1 & P5 & $\mathrm{P} 100$ & & ${ }^{3} \mathrm{H}$-pro \\
\hline 2 & P6 & P55 & & ${ }^{3} \mathrm{H}$-pro \\
\hline 1 & $\mathbf{P} 6^{a}$ & P55 & & ${ }^{3} \mathrm{H}$-pro \\
\hline 1 & $\mathrm{Pg} \mathrm{g}^{a}$ & P60 & & ${ }^{3} \mathrm{H}$-pro \\
\hline 1 & $\mathrm{P} 11^{a}$ & P62 & & ${ }^{3}$ II-pro \\
\hline 2 & P18 & P50 & & ${ }^{3} \mathrm{H}$-pro \\
\hline 2 & $\mathbf{P} 20$ & P46 & & ${ }^{3} \mathrm{H}$-pro \\
\hline
\end{tabular}

$\overline{{ }^{3} \mathrm{H}-\mathrm{thy} \text {, autoradiography following intrauterine injections of }{ }^{3} \mathrm{H} \text {-thymidine at } \mathrm{E} 39}$ or E40 to label layer 4 cells. " $\mathrm{H}$-pro, autoradiography following intraocular injections of ${ }^{3} \mathrm{H}$-proline into the eye ipsilateral to kainic acid-injected hemisphere.

${ }^{a}$ In these animals kainic acid was injected directly into the cortical plate. In all other experiments kainic acid was injected into the white matter underlying visual cortex.

slides. Air-dried sections were dehydrated in graded alcohols, defatted in xylenes, and coverslipped.

Autoradiography. One week to $10 \mathrm{~d}$ following eye injection of ${ }^{3} \mathrm{H}-$ proline the animals were perfused with $4 \%$ paraformaldehyde in $0.1 \mathrm{M}$ sodium phosphate buffer. The brain was removed and postfixed in the same fixative plus $20 \%$ sucrose. The next day, the brain was embedded in a mixture of gelatin and albumin and sectioned in the horizontal plane on a freezing microtome $(20-30 \mu \mathrm{m})$. Autoradiography on these sections was performed as previously described (LeVay et al., 1978; Luskin and Shatz, 1985a).

Immunohistochemistry. Antibodies against the following antigens were used. MAP2 (mouse monoclonal anti-bovine MAP2-3 diluted 1:30) was a gift from Drs. W. Theurkauf, F. Luca, and R. Vallee (Worcester Foundation for Experimental Biology, Shrewsbury, MA); glial fibrillary acidic protein (GFAP; rabbit anti-human polyclonal diluted 1:500) was a gift from Dr. L. Eng (Stanford University, Stanford, CA). Bound antibody was visualized using Vectastain $A B C$ kits (Vector Laboratories, Burlingame, CA), and the chromogen 3,3:pr-diaminobenzidine (DAB; grade II, no. D-5637; Sigma Chemical Co.).

For immunohistochemical staining, $100 \mu \mathrm{m}$ vibratome-cut or $30 \mu \mathrm{m}$ frozen sections were preincubated at $25^{\circ} \mathrm{C}$ for $2 \mathrm{hr}$ in phosphate-buffered saline (PBS) plus $2.5 \%$ bovine serum albumin (BSA) (no. A-4503, fraction V; Sigma Chemical Co.) and 0.3\% Triton X-100 (no. T-6876; Sigma Chemical Co.). This solution was replaced by fresh incubation buffer containing diluted antibody and incubated for $15-24 \mathrm{hr}$ at $4^{\circ} \mathrm{C}$ (freefloating scctions were gently agitated during incubation). $\Lambda$ fter incubation, sections were washed (at $25^{\circ} \mathrm{C}$ ) in PBS (four changes over 30 $\mathrm{min}$ ), followed by $60 \mathrm{~min}$ in secondary antibody (1:200), and then washed again (four changes over $30 \mathrm{~min}$ ) with $50 \mathrm{~mm}$ Tris-buffered saline (TBS: $50 \mathrm{~mm}$ Tris- $\mathrm{HCl}, 150 \mathrm{~mm} \mathrm{NaCl}, \mathrm{pH} 7.5$ ) and reacted with the addition of $0.5 \mathrm{mg} / \mathrm{ml}$ DAB (3,3'-diaminobenzidine) with $0.0075 \%$ $\mathrm{H}_{2} \mathrm{O}_{2}$. The sections were then washed again $(20 \mathrm{~min}$ with two changes of TBS). Sections were mounted on subbed slides, air dried, taken through 
A

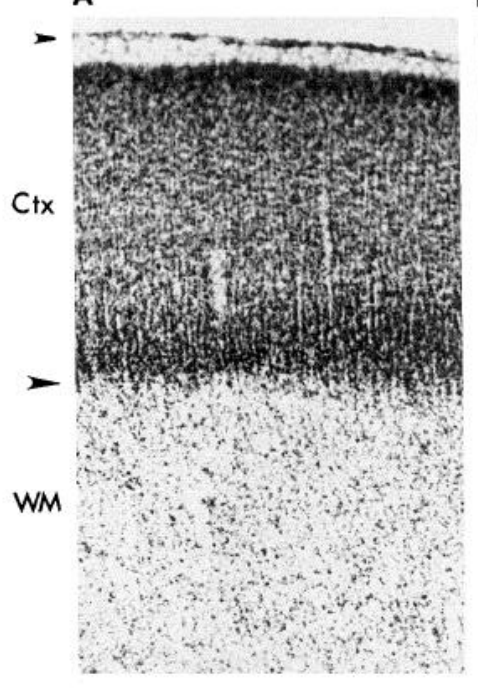

B

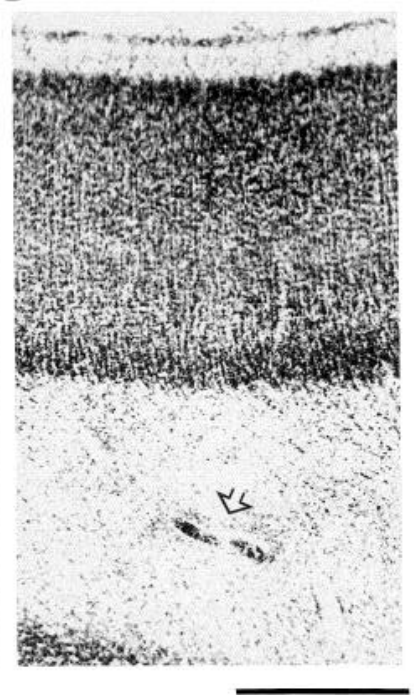

Figure 1. The histology of visual cortex at P10 following kainic acid injection into the white matter at $\mathrm{P} 2$. $A$, Cresyl violet stain of the salineinjected hemisphere shows the dense packing of cells in the cortex and a relatively sparse distribution of darkly stained cells (subplate cells) in the white matter. $B$, In the kainic acid-injected hemisphere the distribution of cells in the cortex is essentially identical to the saline-injected control. Note, however, that the number of darkly stained cells in the white matter is significantly reduced. The arrow points to the center of the kainic acid injection site that is restricted to the middle of the white matter. $C t x$, cortex; $W M$, white matter. Scale bar, $500 \mu \mathrm{m}$.

three washes of distilled water, followed by dehydration in graded ethanols. Sections were then immersed in xylene for 10-30 min and cover slipped with Permount (Fisher Scientific Co.).

\section{Results}

The results are presented in three parts. In the first section we describe experiments that examine the specificity of subplate ablations achieved by injecting kainic acid into the white matter of neonatal cats. In the next section we describe the consequences of ablating subplate neurons right after LGN axons have grown into layer 4 (first postnatal week) on the formation of ocular dominance columns and the cytoarchitecture of layer 4 . Finally, we report on our observations on the distribution of LGN axon terminals following subplate ablations at the onset of the normal period of segregation (third postnatal week).

\section{Acute effects of kainic acid injections on the cellular constituents of the white matter and cerebral cortex}

Subplate neurons were ablated in neonatal cats by injecting the excitotoxin kainic acid into the white matter underlying primary visual cortex (area 17) in one hemisphere between P2 and P20. At these ages, most of the axons from the LGN have arrived within, and are restricted to, layer 4 of visual cortex (LeVay et al., 1978; Shatz and Luskin, 1986; Ghosh and Shatz, 1992a). Fluorescent latex microspheres were added to the kainic acid solution prior to injection in order to locate the injection site at the end of the experiment. Since these microspheres are taken up and retrogradely transported by healthy axons, they also allowed us to monitor the fate of LGN neurons whose axons were close to the injection site at the time of the kainic acid injection.

The extent of the lesion following an injection of kainic acid into the white matter was determined by cresyl violet staining

and by MAP2 immunohistochemistry. Figure 1, $A$ and $B$, shows the effects of a kainic injection made at P2 on the histology of the cortex at P10. Compared to the uninjected hemisphere at P10 (Fig. 1 $A$ ), the histology of the cortex in the kainic acidtreated hemisphere is essentially unaltered (Fig. 1B). In these cresyl violet-stained sections the pattern of cortical lamination is normal, with the deep cortical layers (5 and 6) clearly visible, and the superficial layers still in the process of forming as the last cells complete their migrations to layers 2 and 3 (Shatz and Luskin, 1986). However, fewer large cells stained with cresyl violet could be seen in the white matter near the injection site, which, as shown in Figure $1 B$, was nicely restricted to the white matter.

To determine the extent of neuronal damage caused by neonatal kainate injections into the white matter, we immunostained adjacent sections for MAP2, which stains the somata and dendrites of neurons (Matus et al., 1981; Chun and Shatz, 1988b). As shown in Figure 2, $A$ and $B$, the subplate neurons near the injection site are indeed missing following a white matter injection of kainic acid. However, those some distance away in the white matter remain unaffected. The area over which MAP2positive cells were ablated showed some variation between experiments. The example in Figure $2 A$ represents a particularly restricted deletion. In most experiments at 2 weeks after injection, subplate neurons $1-3 \mathrm{~mm}$ around the injection sites were deleted. Frequently (as in Fig. $3 C$ ), subplate neurons all the way to the base of the cortical plate were missing, but there was no detectable loss of MAP2 immunoreactivity in the cortical plate itself.

To ascertain whether kainic acid deletes other cell types close to the injection site, we also immunostained adjacent sections for glial fibrillary acidic protein (GFAP), an astrocyte-specific marker (Levitt and Rakic, 1980). As shown in Figure 2, $C$ and $D$, GFAP-positive cells are present and are apparently unaffected by kainic acid, as expected from previous studies (Coyle et al., 1978, 1981). It has also been previously shown that kainate injections into the fetal brain do not alter radial glial cell morphology (Ghosh et al., 1990) and glial-specific vimentin immunoreactivity in the white matter (Ghosh and Shatz, 1993). Therefore, it appears that glial cells are present following kainic acid injections.

Since we were interested in examining the segregation of afferents in layer 4 , it was of particular importance to verify that layer 4 neurons were present following an injection of kainic acid into the white matter. To do so, we labeled layer 4 cells at their birthdates (E40; Luskin and Shatz, 1985b) with ${ }^{3} \mathrm{H}$-thymidine and then examined autoradiographs of cortex at P19 following an injection of kainic acid at P7. Results, shown in Figure $3 A$, indicate that at this age there is no obvious loss of ${ }^{3} \mathrm{H}$-thymidine-labeled neurons within layer 4 , with the exception of two small patches of reduced labeling directly above the injection site (discussed further below). To verify that the kainic acid ablation of subplate neurons was successful in this experiment, an adjacent section was stained for MAP2. As shown in Figure $3, B$ and $C$, there was a clear ablation of subplate neurons in the experimental hemisphere. Thus, our observations based on cresyl violet staining, MAP2 and GFAP immunohistochemistry, and ${ }^{3} \mathrm{H}$-thymidine autoradiography provide support for the contention that there is little if any immediate effect of kainic acid injected in the white matter on cortical plate neurons or glial cells. The major effect of such injections appears to be a selective elimination of subplate neurons. 

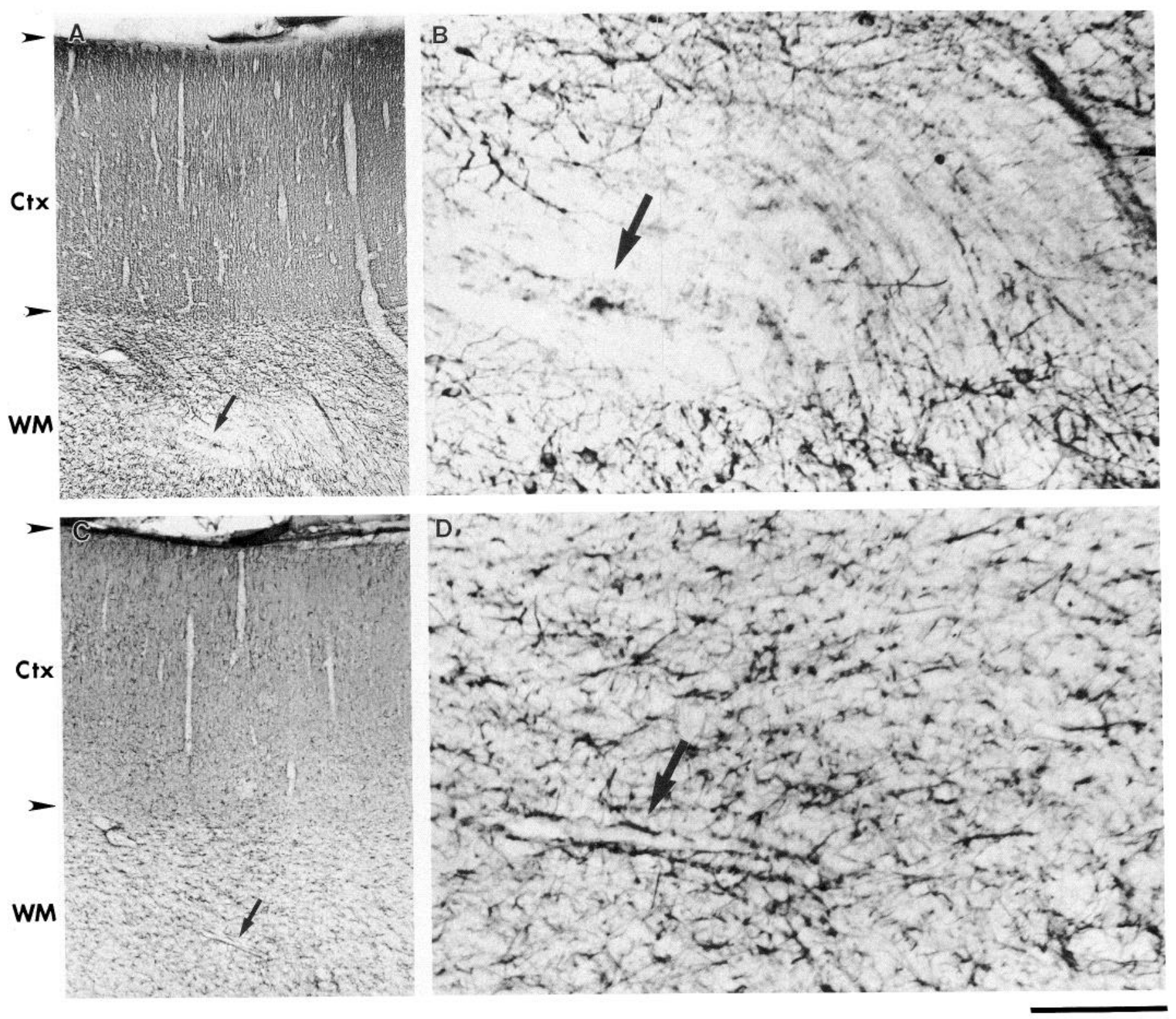

Figure 2. The effect of white matter kainic acid injections on neuronal and glial cells. $A$ and $B$, MAP2 immunostaining at P10 following a white matter kainic acid injection (arrow) at P2. Although there is no effect on the immunoreactivity seen in the cortex $(A)$, at higher magnification it is evident that there has been a loss of immunoreactivity associated with subplate neurons near the injection site $(B)$. $C$ and $D$, GFAP immunostaining of a section adjacent to that shown in $A$ reveals no obvious changes in GFAP-immunoreactive cells either in the cortex or in the immediate vicinity of the injection site. $C t x$, cortex; $W M$, white matter. Scale bar: $A$ and $C, 500 \mu \mathrm{m} ; B$ and $D, 100 \mu \mathrm{m}$.

\section{Consequence of subplate neuron ablation during the first postnatal week on the segregation of LGN axons within layer. 4}

We next examined the effect of neonatal subplate ablations on the formation of ocular dominance columns within layer 4 . Subplate neurons were ablated in 19 animals during the first postnatal week (Table 1). At these ages LGN axons representing the two eyes have just grown into layer 4 and are completely intermixed; they do not begin segregating into ocular dominance columns until about $\mathrm{P} 21$. The status of ocular segregation within layer 4 of visual cortex was assessed by transneuronal transport of intraocularly injected ${ }^{3} \mathrm{H}$-proline after $\mathrm{P} 40$, at a time when segregation is normally close to completion (LeVay et al., 1978). An example of the pattern of ocular dominance columns in layer
4 of a normal cat at P44 is shown in Figure $4 A$. In autoradiographs, radioactive label transported transneuronally from the ipsilateral eye can be detected in patches within layer 4 of primary visual cortex. The labeled patches, which represent LGN axon terminal arbors, occur in a regular linear array with a periodicity of about $1 \mathrm{~mm}$. Since in normal animals the ocular dominance columns are much sharper in layer 4 ipsilateral to an eye injection (Fig. 1A; LeVay et al., 1978), all of the results presented here will be from kainic acid injections made into the cortex ipsilateral to the eye injection.

In marked contrast to the normal segregated pattern of geniculate afferents, transneuronally transported label is nearly uniformly distributed within layer 4 following ablation of subplate neurons. The consequences of ablating subplate neurons at P6 on the pattern of transneuronal labeling in layer 4 at P55 
A

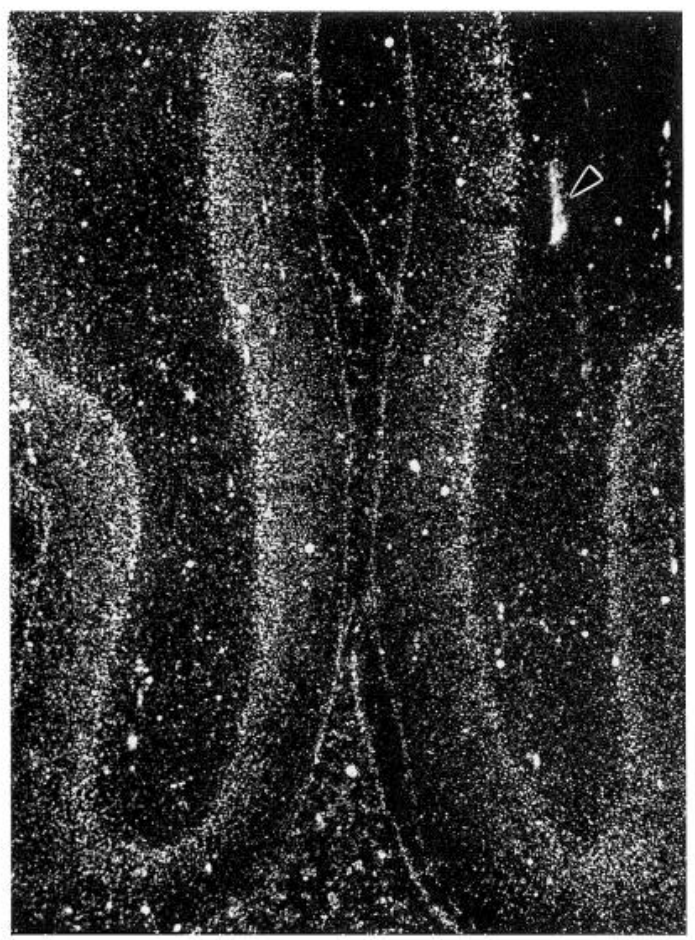

B

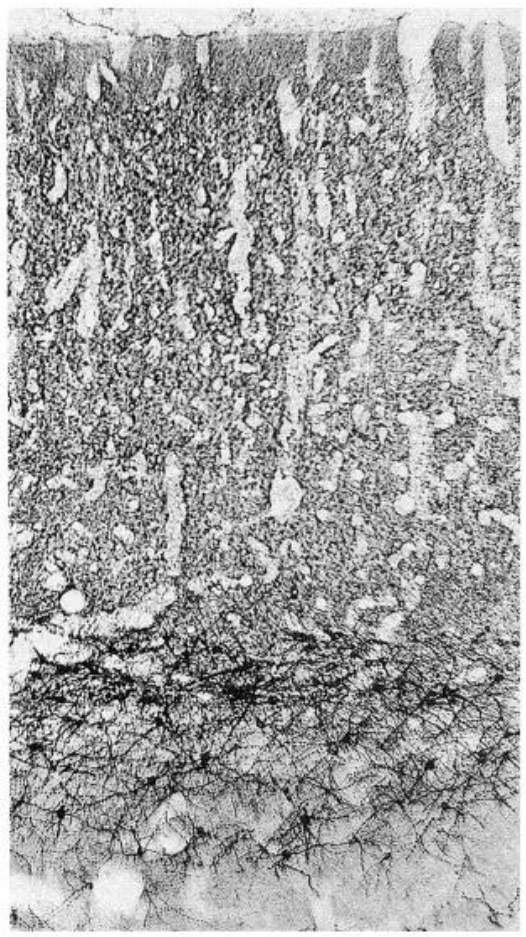

C

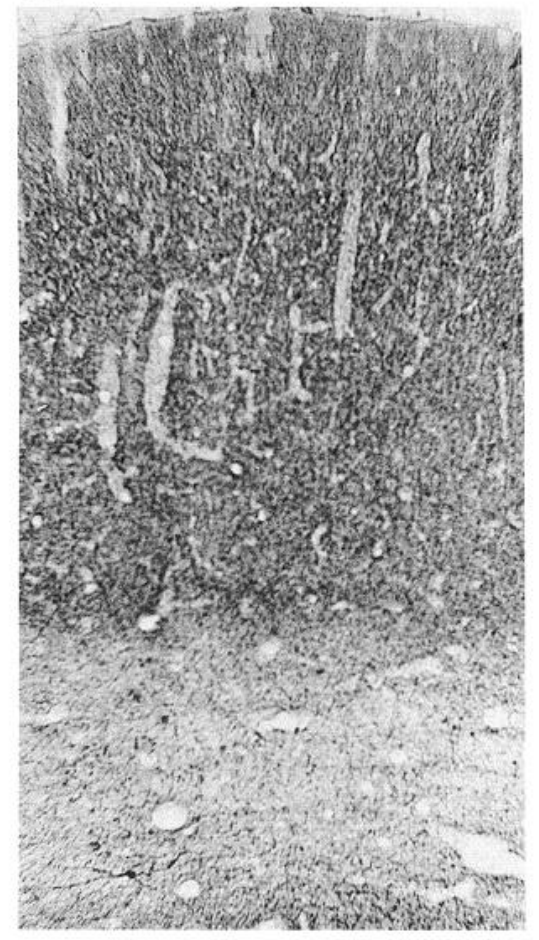

Figure 3. Effect of white matter kainic acid injections on layer 4 cells and subplate cells examined at the onset of the period of segregation. $A$, Following labeling of layer 4 neurons at E40, kainic acid was injected into the white matter of the right hemisphere at P7 and the consequences examined at P19 by emulsion autoradiography of horizontal sections. A narrow band of ${ }^{3} \mathrm{H}$-thymidine-labeled layer 4 cells is evident in both the control and kainic acid-injected hemispheres, indicating that the majority of layer 4 cells are present following the white matter kainic acid injection $12 \mathrm{~d}$ earlier. Note, however, that immediately above the injection site (arrowhead) there are two small zones of reduced ${ }^{3} \mathrm{H}$-thymidine labeling. This reduction reflects cell loss that is just detectable at this age (see also Fig. 11 and text for further details). $B$ and $C$, MAP2 immunoreactivity of a section adjacent to that shown in $A$ confirms that the injection shown in $A$ was effective in ablating subplate neurons. While a large number of subplate neurons are present in the white matter of the saline-injected hemisphere $(B)$, they are virtually all missing in the kainic acid-treated hemisphere $(C)$. Scale bar: $A, 2.3 \mathrm{~mm} ; B$ and $C, 500 \mu \mathrm{m}$.

are shown in Figure $4 B$. Comparison of the labeling in the kainic acid-injected right hemisphere with the normal pattern of labeling (Fig. $4 A$ ) clearly shows that ocular dominance columns have failed to form in a region that would normally contain distinct columns (region between arrowheads). Figure $4 C$ shows the pattern of transneuronal labeling at P70 following an injection of kainic acid into the white matter underlying the posterior half of visual cortex at P2. In this particular case, it is striking that columns have failed to form in the posterior visual cortex but appear normal in the anterior visual cortex, far from the kainic acid injection site. Note that the labeling is less dense in posterior visual cortex, but this does not imply loss of LGN inputs since, in the absence of ocular dominance columns, axon terminals presumably must distribute themselves over twice the normal target territory.

A comparison of the transneuronal labeling is shown at higher magnification in Figure 5. Figure $5 B$ shows the pattern of transneuronal labeling at P55 following a white matter kainic acid injection at P6 (this is from a different experimental animal than that shown in Fig. $4 B$ ). The lack of columns stands in striking contrast to the pattern normally seen by P44 (Fig. $5 A$ ). This unsegregated pattern of labeling within layer 4 was observed in 10 of the 11 kittens in which transneuronal transport was examined following kainic acid injection into the white matter between $\mathrm{P} 2$ and $\mathrm{P} 7$. It is unlikely that the process of ocular segregation has simply been delayed in these animals, since the transneuronal label in the cortex is still uniform at P100, almost 3 months after the normal onset of segregation and 2 months after ocular segregation would normally be complete (cf. Ghosh and Shatz, 1992b). In the eleventh kainic acid-treated kitten the periodicity of ocular dominance columns was also perturbed, but there had clearly been some segregation of LGN afferents within layer 4.

In every case where the kainic acid injection was restricted to a small region of the white matter underlying visual cortex, ocular dominance columns were absent in layer 4 immediately overlying the lesion site, but the segregation of afferents was not perturbed in the entire hemisphere. For example, as was noted in Figure $4 C$, the pattern of transneuronal labeling within the cortex in areas near the injection site is nearly uniform, but the normal periodic patches of label can be seen further anterior with increasing distance from the site of kainic acid injection.

A possible concern for the interpretation of this experiment is that kainic acid injected into the white matter might diffuse into the cortical plate and directly affect LGN axon terminals. To deal with this concern, in three animals injections of kainic acid and fluorescent microspheres were made directly into the cortical plate during the first postnatal week. The concentration 
A

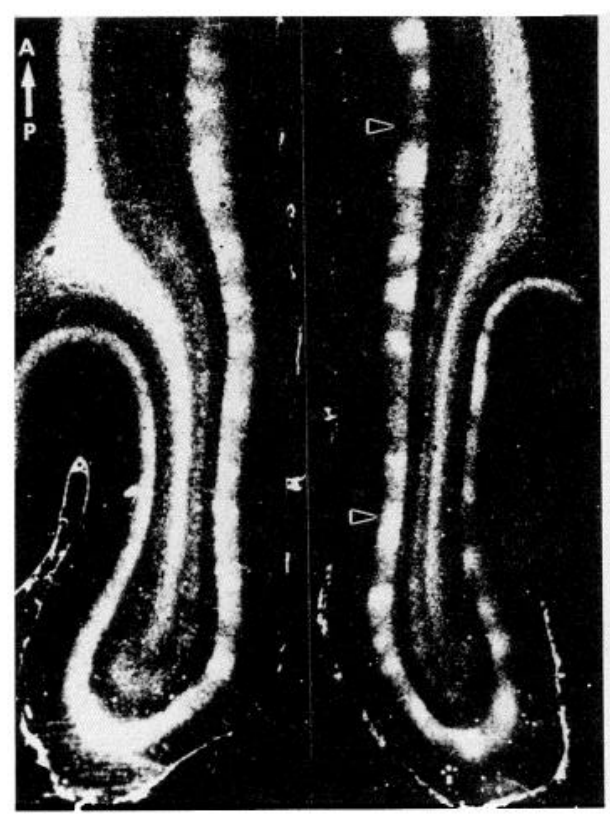

B

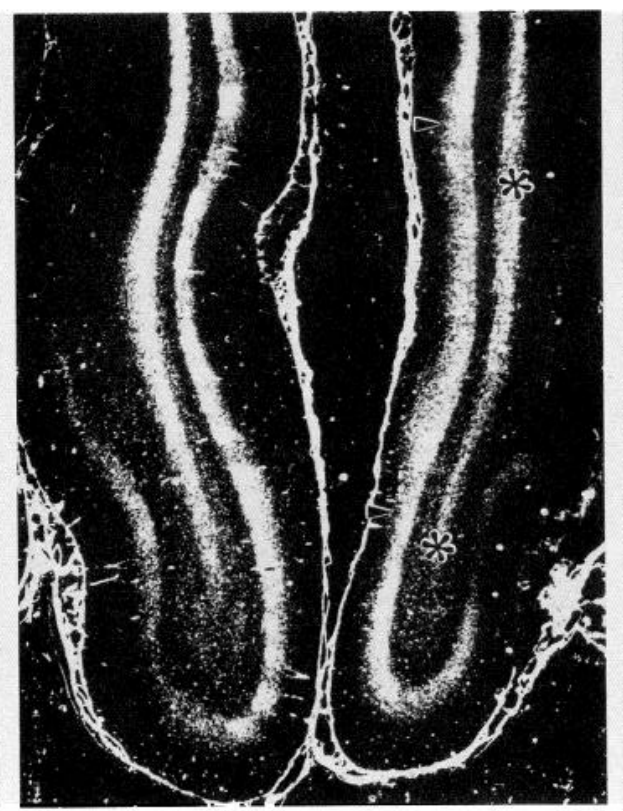

C

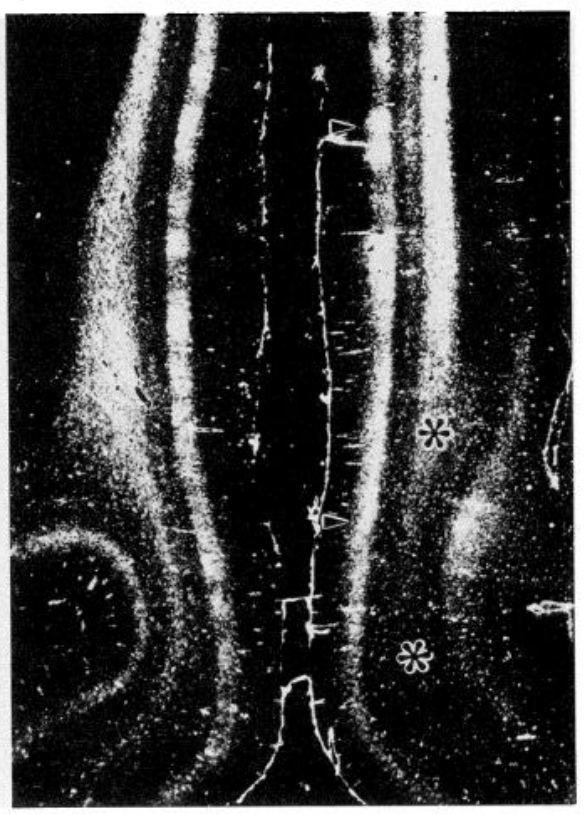

Figure 4. Ocular dominance columns fail to form in primary visual cortex following neonatal kainic acid injections into the white matter. $A$, The normal pattern of ocular dominance columns at P44 revealed in dark-field optics following transneuronal transport of ${ }^{3} \mathrm{H}$-proline (radioactively labeled axons and terminals appear white). Note that the pattern of ocular dominance columns is much sharper in the hemisphere ipsilateral to the eye injection (arrowheads). B, The pattern of transneuronal labeling in visual cortex at P55 following a white matter kainic acid injection at P6 indicates that ocular dominance columns have failed to form. In contrast to the ocular dominance patches of normal animals $(A$; compare region between arrowheads), the labeling of geniculocortical terminals is uniform within layer 4 in this animal. $C$, The pattern of transneuronal labeling at P70 following a white matter kainic acid injection only into posterior visual cortex at P2. Ocular dominance patches are absent in the posterior region of visual cortex near the injection site but are present farther anterior. The approximate locations of the kainic acid injection sites, as determined by referring to the location of injected fluorescent latex microspheres in relevant nearby sections, are indicated by asterisks in $B$ and $C$. In these horizontal sections anterior is to the top; the hemisphere injected with kainic acid is indicated by arrowheads and is ipsilateral to the ${ }^{3} \mathrm{H}$-proline-injected eye. Scale bar, $2 \mathrm{~mm}$.

and volume of kainic acid injected into the cortical plate was identical to that used in the white matter injections. Examination of the pattern of the geniculocortical projection at P60 revealed that within a region of the cortical plate injected with kainic acid at $\mathrm{P} 9$, segregation had proceeded normally, as shown in Figure 6 (see also Fig. 12C,D). This observation suggests that LGN terminals are not directly affected by kainic acid, at least during the first postnatal week. More generally, it suggests that

\section{A}

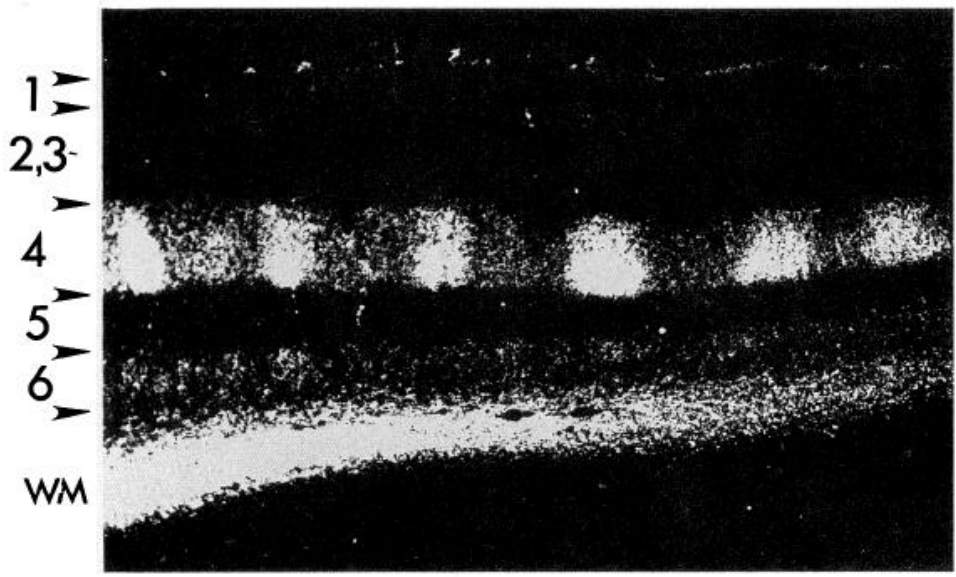

B

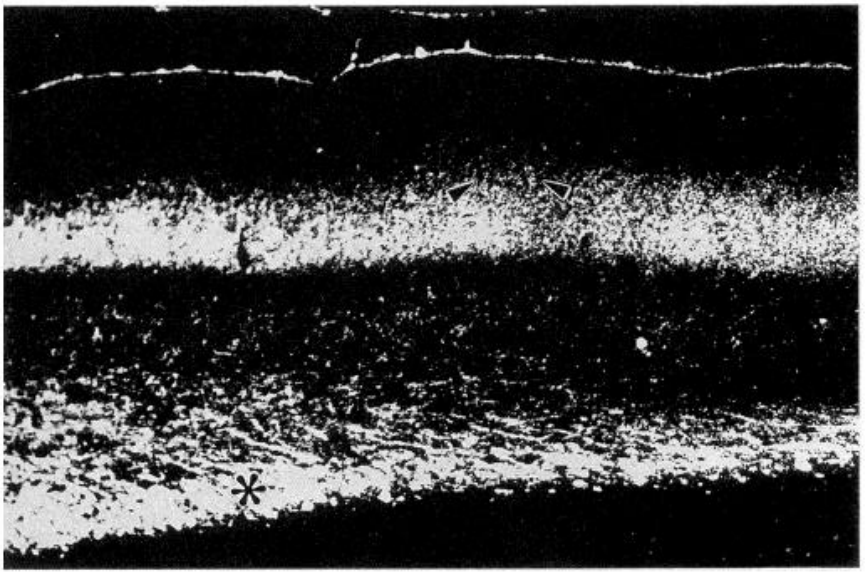

Figure 5. A comparison of the pattern of transneuronal labeling in the visual cortex between a normal and a kainic acid-treated animal. A, In the normal visual cortex at P44 discrete ocular dominance patches are restricted to layer 4 . Some transneuronal label can also be seen within layer 6 and the white matter. $B$, Following a white matter kainic injection at P6 the transneuronal labeling seen at P55 is completely uniform. The transneuronal label, however, is largely restricted to layer 4 as in normal animals. (Note, however, some label at base of layer 3: arrowheads.) The approximate location of the nearest kainic acid injection is indicated by an asterisk. Scale bar, $1 \mathrm{~mm}$. 

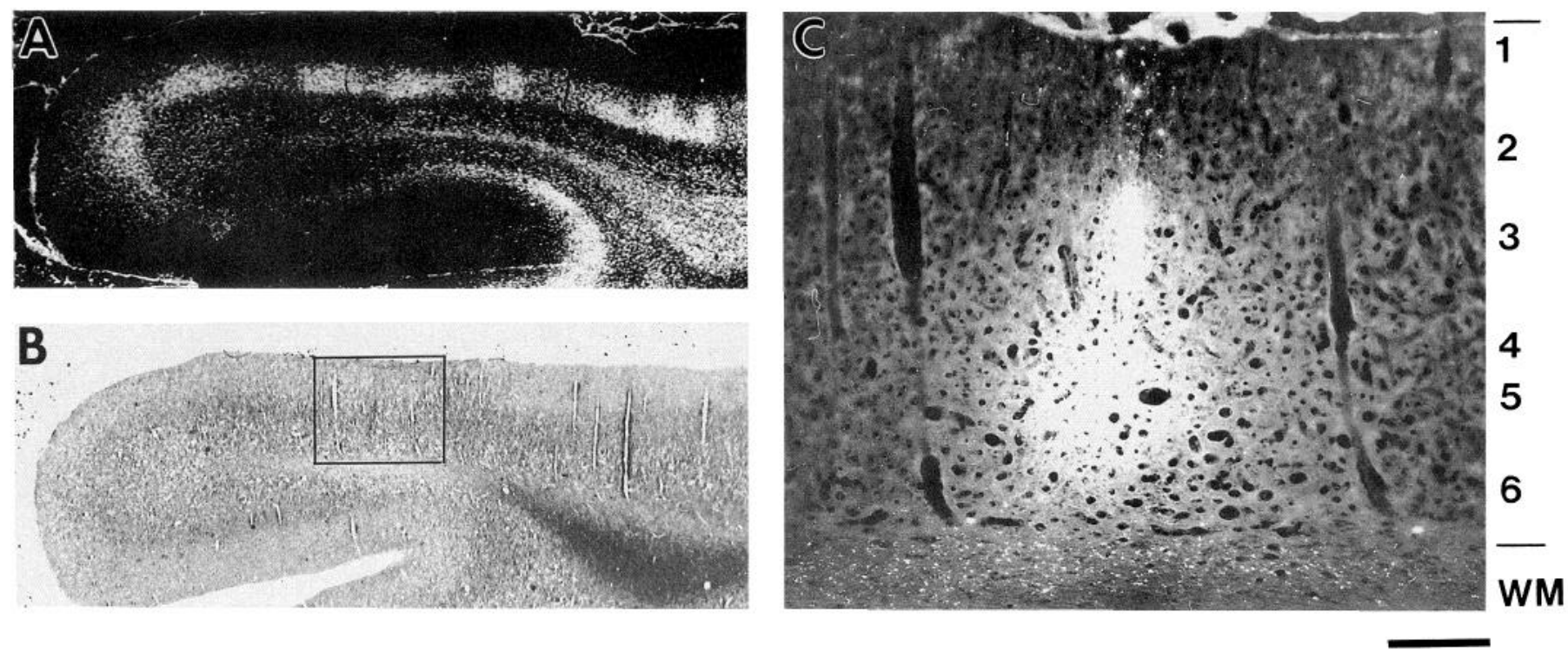

Figure 6. Kainic acid injections directly into the cortex do not disrupt ocular dominance column formation. $A$, The pattern of transneuronal labeling in visual cortex at P60 following an injection of kainic acid into the cortical plate at P9 reveals the normal array of ocular dominance patches in layer 4. $B$, A phase-contrast micrograph of a section adjacent to that shown in $A$ indicates the region of the cortical plate injected with kainic acid. $C$, A high-power fluorescent micrograph of the boxed region in $B$ confirms that the injection site (marked by fluorescent microspheres) was restricted to the cortex. Note also the many retrogradely labeled cells in the white matter and base of layer 6 , as expected since these cells send recurrent axon collaterals into layer 4 . $W M$, white matter. Scale bar: $A$ and $B, 2 \mathrm{~mm} ; C 350 \mu \mathrm{m}$.

passive diffusion of kainic acid from the white matter into the cortical plate is unlikely to be responsible for the perturbations we see in ocular dominance column formation.

Since the radioactive label is taken up by LGN neurons via transfer from retinal ganglion cell terminals, it is possible that a rearrangement of retinal terminals within the LGN causes the observed unsegregated pattern of labeling within the cortex following a kainic acid injection. This possibility can be ruled out, since the segregation of retinal afferents within the LGN is not perturbed in the subplate-ablated brains (Fig. 7). The ipsilateral retinal input to the $\mathrm{LGN}$ is tightly restricted to the appropriate layers. Thus, barring some unprecedented turnover of the ${ }^{3} \mathrm{H}$ proline in the cortex, the pattern of transneuronal label in kainic acid-injected animals must certainly reflect unsegregated geniculocortical afferents. The kainic acid injections also do not cause detectable atrophy of LGN cell bodies, as can be seen in the cresyl violet-stained section of Figure $8 \mathrm{~A}$. At least some of the LGN neurons in this section project to the cortex overlying the injection site, as demonstrated by the fact that they contain fluorescent microspheres (Fig. $8 B-D$ ). The microspheres were
A

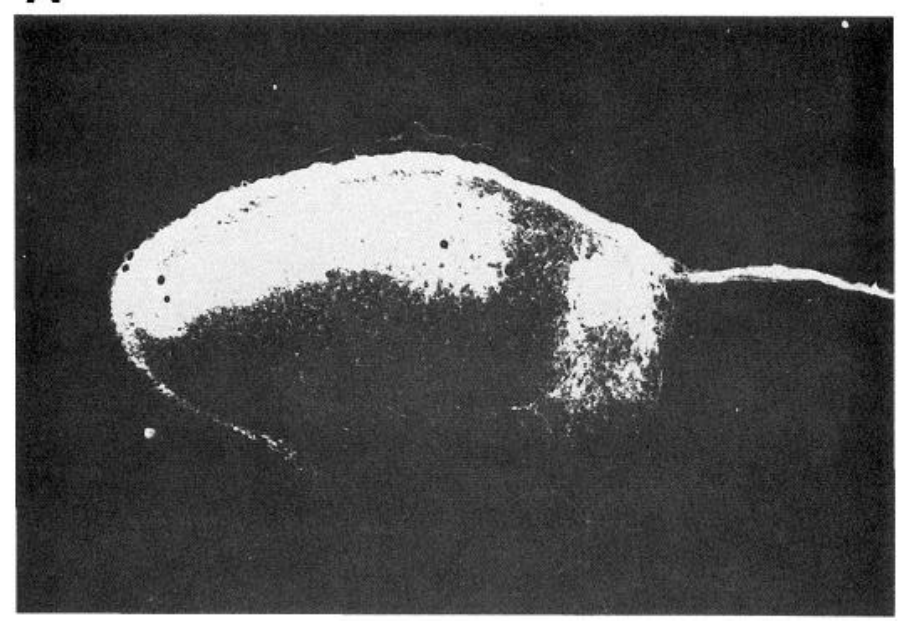

B

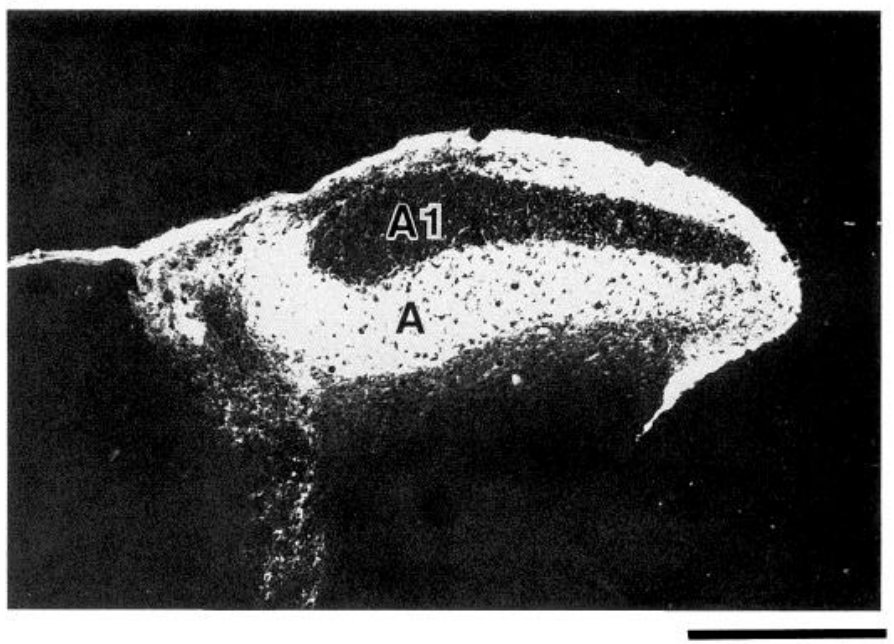

Figure 7. $A$ and $B$, Pattern of transneuronal labeling at P70 in the LGN ipsilateral $(A)$ and contralateral $(B)$ to the ${ }^{3} \mathrm{H}$-proline-injected eye following kainic acid injection at P2 in the hemisphere ipsilateral to eye injection. As in normal animals, label in the ipsilateral LGN $(A)$ is restricted to layer $\mathrm{A} 1$ and label in the contralateral LGN $(B)$ is restricted to layer A. In these horizontal sections, posterior is to the top of the figure. Despite normal segregation of afferents in the LGN, transneuronal labeling in layer 4 of this animal was uniform, indicating that LGN axons had failed to segregate. Scale bar, $1 \mathrm{~mm}$. 

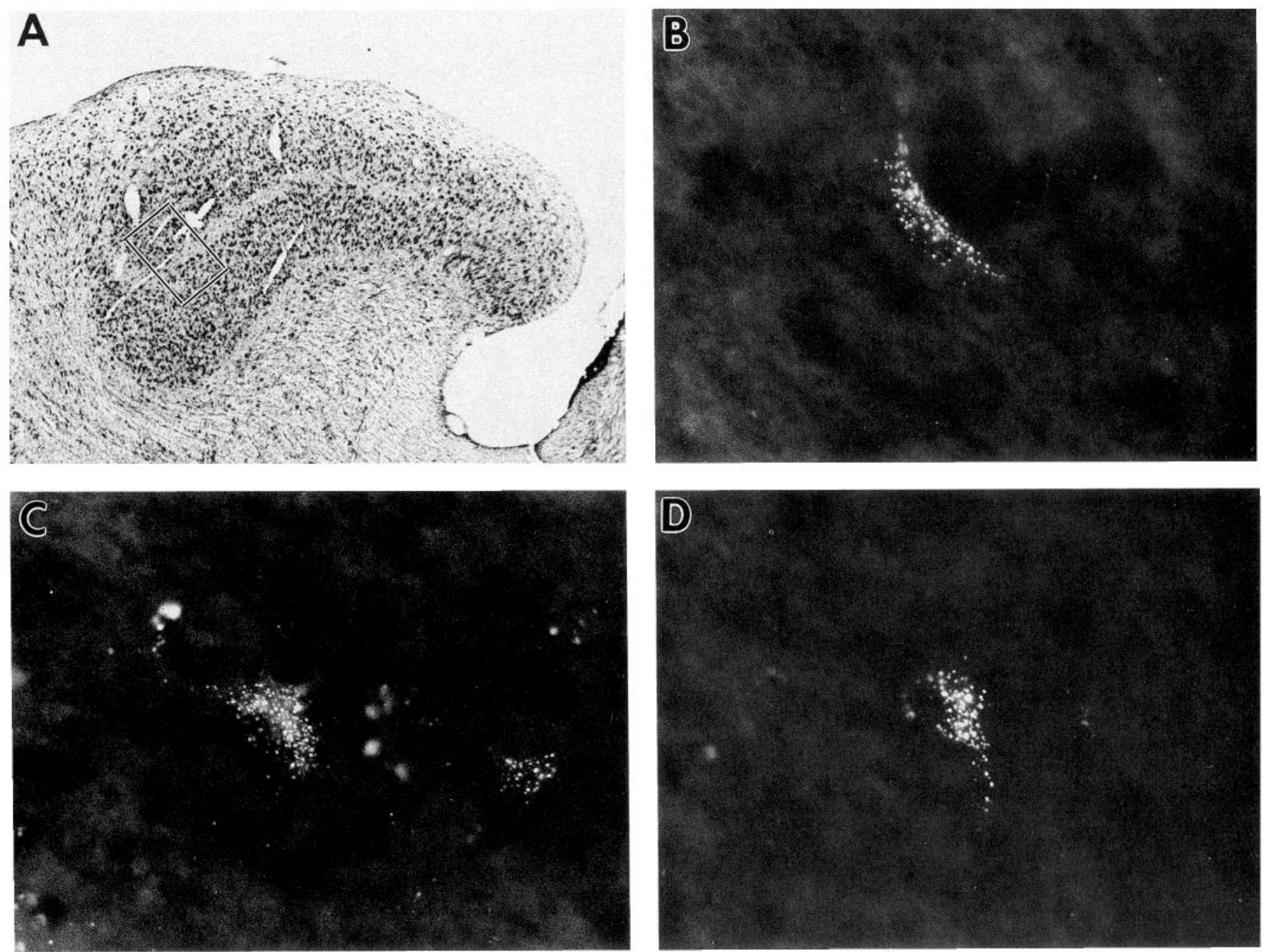

Figure 8. LGN neurons with terminals close to the kainic acid injection site can survive at least for several weeks postinjection. A, The histology of the LGN (shown in a horizontal section; posterior is to the top, medial is to the left) at P55 following P6 kainic acid injection into the white matter underlying visual cortex indicates that the cellular organization of the LGN is not obviously perturbed by this treatment. $B-D$, Fluorescent micrographs from the boxed region in $A$ indicate that LGN neurons with terminals close to the injection site retrogradely transport fluorescent microspheres coinjected with kainic acid and survive at least to the end of the experiment. Scale bar: $A, 1 \mathrm{~mm} ; B-D, 50 \mu \mathrm{m}$.

available for uptake and retrograde transport to the LGN at P6, when some LGN axons still extend branches within the subplate (Ghosh and Shatz, 1992a) where the injection was made.

Figure 8 also demonstrates that LGN terminals close to the injection site seem not to be damaged directly by the kainic acid, as they are capable of retrogradely transporting the microspheres coinjected with kainic acid back to the parent cell bodies within the LGN. These observations suggest that the uniform pattern of transneuronal labeling seen in layer 4 following neonatal subplate ablations is due to the failure of LGN axon terminals to segregate rather than a reorganization of retinogeniculate axons.

\section{Consequences of subplate neuron ablation on the cytoarchitecture of visual cortex}

Although our observations on the histology of the cortex at short times after kainic acid injections indicate that the acute effects of white matter kainic acid injections appear to be limited to subplate neurons, the failure of LGN axons to segregate prompt- ed us to examine the long-term consequences of subplate ablation on the histology of visual cortex, particularly layer 4 . We therefore examined the cytoarchitecture of visual cortex in subplate-ablated animals where LGN axons had failed to segregate into ocular dominance columns. Figure 9 shows a pair of highmagnification photos of cresyl violet-stained sections from a normal animal at P44 and from a subplate-ablated animal at P70 taken from a region of visual cortex where ocular dominance columns had failed to form. It is evident from these sections that there is a restricted but significant disruption of cortical lamination in the treated animals, particularly at the base of layer 4 (Fig. 9B, asterisk). Close inspection reveals that there is a loss of many of the small stellate cells of layer 4 that creates the appearance of a cell-sparse strip at the border between layers 4 and 5. This strip is even more evident at higher magnification (Fig. 9C,D), in which a population of very small cell bodies, possibly glia, can be discerned. In contrast, the cytoarchitecture of the other cortical layers appears normal. Inspection of many cresyl violet sections and their adjacent auto- 

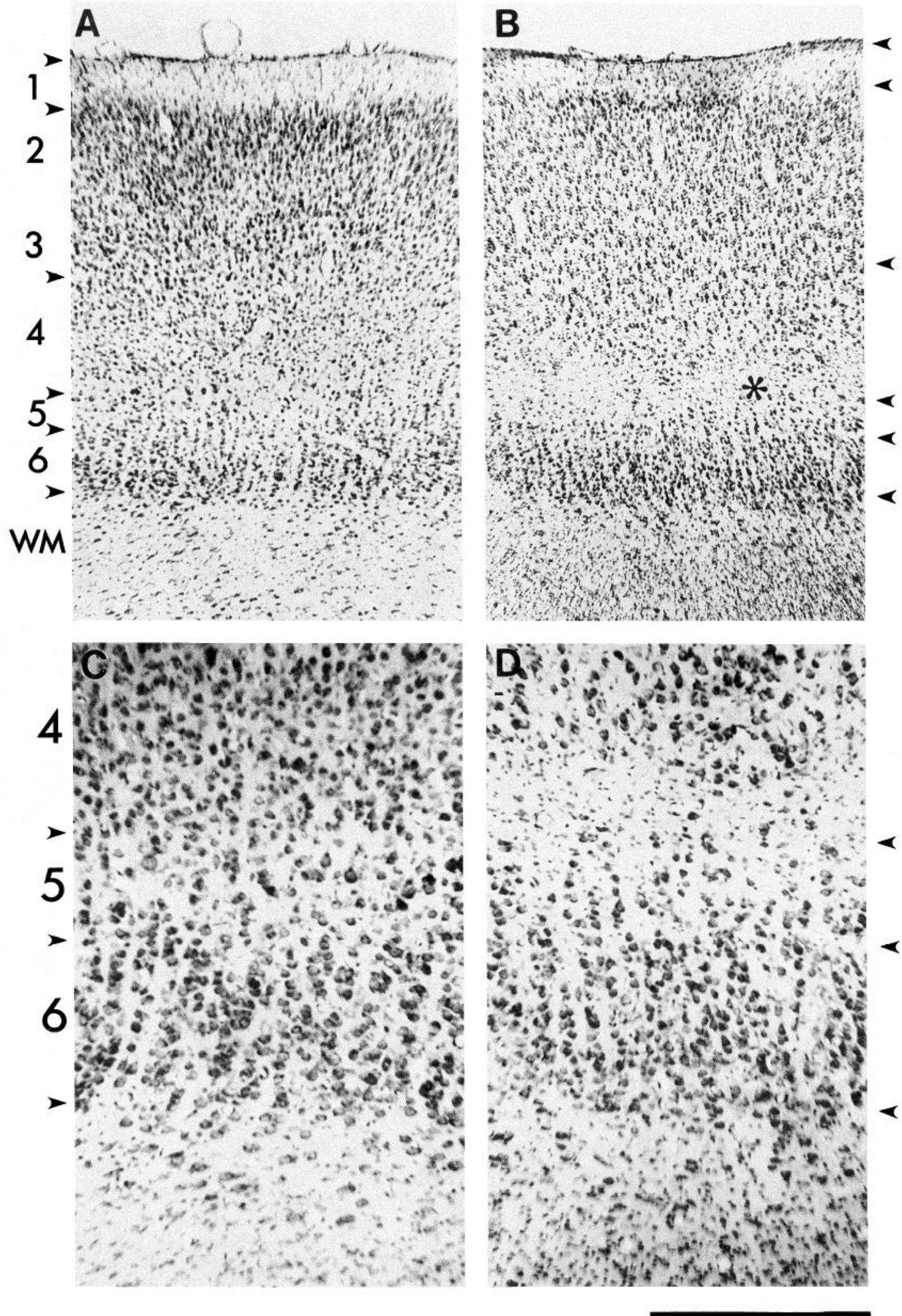

Figure 9. The effect of white matter kainic acid injections on cortical histology. A, Cresyl violet-stained section from the visual cortex of a normal animal at P44 shows the cortical layers identifiable by distinct cell densities and cell sizes. $B$, Cresyl violet-stained section from the visual cortex of an animal at P70 that had received a white matter kainic acid injection at P2. Whereas the overall thickness of the cortex is comparable to normal, there is an apparent loss of darkly stained cells at the base of layer 4 (asterisk). $C$ and $D$, Higher-magnification micrographs of $A$ and $B$ indicate that the region of reduced staining in layer 4 contains many small, lightly stained cells. These are likely to be glia, but may also include atrophied neurons. Scale bar: $A$ and $B, 1 \mathrm{~mm} ; C$ and $D, 370 \mu \mathrm{m}$. 

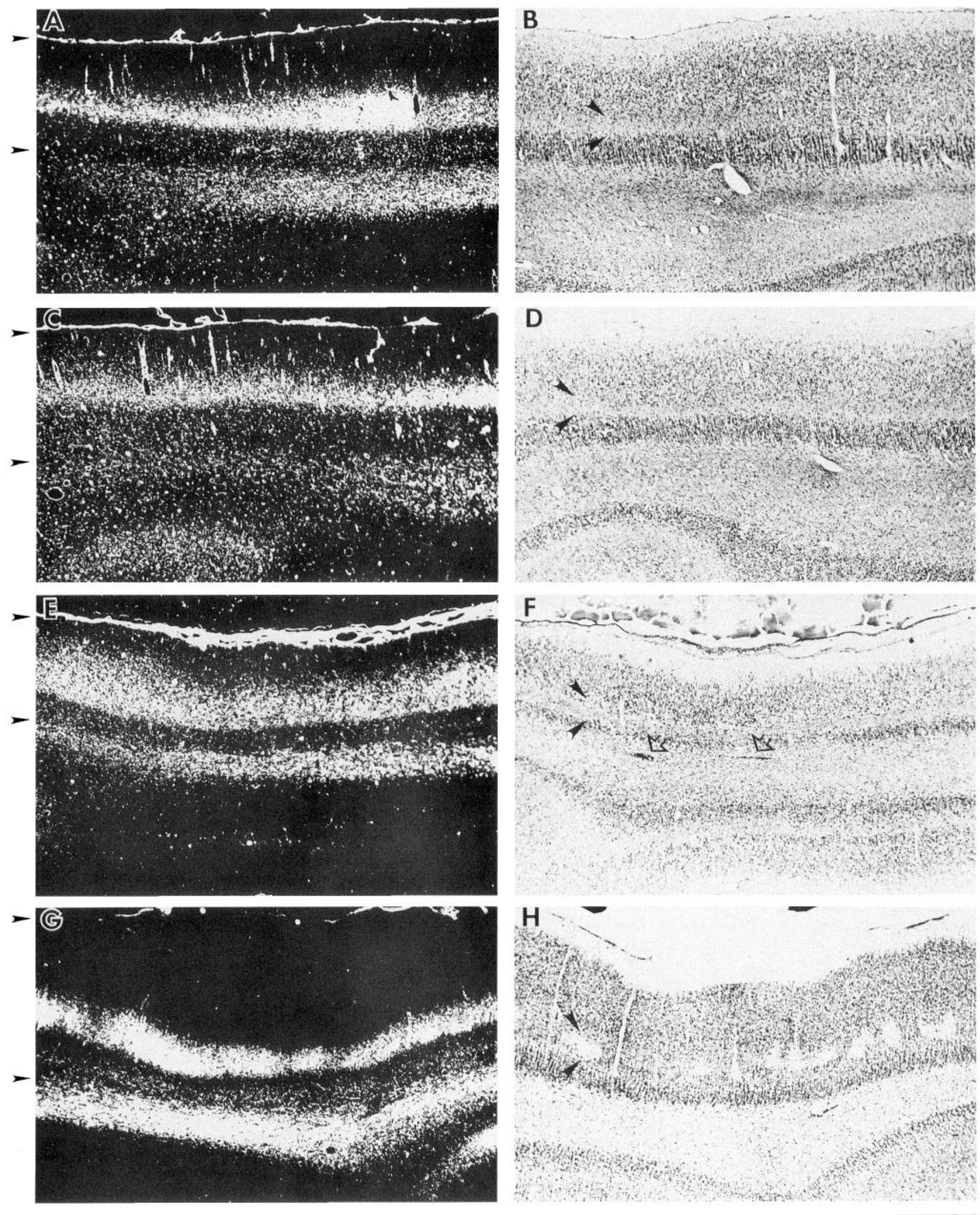

Figure 10. The location of transneuronally labeled geniculocortical afferents in animals injected with kainic acid during the first postnatal week compared to cortical histology. Transneuronally labeled geniculocortical afferents in a region of cortex close to the injection site are shown at P70 $(A$ and $C)$, P55 $(E)$, and P47 $(G)$ following kainic acid injections at P2, P6, and P3, respectively. In each of the cases, ocular dominance columns have failed to form. The histology of the adjacent sections is shown in $B, D, F$, and $H$. In each case, a strip of reduced cresyl violet staining is evident at the base of layer 4 (arrowheads). In $F$, the remnants of the white matter injection sites are indicated by arrows. $G$ and $H$ represent a case of severe cell loss in layer 4 in patches that are locally devoid of transneuronal label. Scale bar, $1 \mathrm{~mm}$. 
radiographs indicates that this abnormal laminar organization is only present in regions where the LGN axons have failed to segregate. Examples of the variations seen in lamination are shown in the low-magnification photos of Figure 10. Although the extent of the cellular disruption could sometimes be quite significant (as in the large cell-free patches seen in Fig. $10 \mathrm{H}$, arrowheads), in every case the primary disruption was restricted to the base of layer 4 where a cell-sparse zone could always be seen.

Evaluation of the sequence of events that leads to these cytoarchitectural abnormalities indicates that the first cellular changes within the cortical plate are not evident immediately following the ablation of subplate neurons, but rather emerge 2-3 weeks later. For example, following an injection of kainic acid at P4, the first cellular changes within the cortical plate were just detectable by P18. As shown in Figure 11, $A$ and $C$, small cell-sparse patches in the lower hall of layer 4 can be detected with cresyl violet staining. At higher magnification (Fig. $11 C)$, these sparse zones apparently contain very small cell bodies. Immunostaining with an antibody against MAP2, which is neuron specific (Fig. $11 B, D$ ), also indicates a loss of immunoreactivity within this region of layer 4 , confirming that the subplate ablation somehow affects a neuronal population within the cortex. Therefore, the ablation of subplate neurons appears to result in a delayed but significant and selective loss of a subset of layer 4 neurons.

To verify that the effect on layer 4 cortical cells of kainic acid injections into the white matter was not a direct consequence of the kainic acid diffusing into the cortex, in a separate set of experiments we injected kainic acid directly into the cortical plate at P6 and examined the consequences at P55. The center of the injection site, again marked with fluorescent microspheres, was located mostly in layers 4 and 5, as shown in Figure $12 D$. In contrast to white matter kainic acid injections (Fig. $12 A, B)$, a direct cortical injection at P6 did not result in an obvious perturbation of the cresyl violet staining close to the injection site (Fig. 12C). This observation is consistent with the reasonable suggestion that at these early neonatal ages, cortical neurons are sufficiently immature that they are still immune to the effects of excitotoxic damage (Coyle et al., 1978, 1981), and they complement our earlier observation that kainic acid injections into layer 4 also do not prevent the formation of ocular dominance columns (Fig. 6). The results of this experiment make it highly unlikely that consequences of kainic acid injection into the white matter on layer 4 neurons is a direct and immediate excitotoxic effect. Rather, it is more likely a secondary, transneuronal effect caused by the deletion of subplate neurons.

\section{Effect of timing of the kainic acid injection on the segregation of geniculocortical axons}

In the initial set of experiments we examined the consequences of subplate injections made during the first postnatal week. At these times the LGN axons have just grown into layer 4 , and following kainic acid ablation of subplate neurons they fail to segregate into ocular dominance columns. We wondered whether a similar result would be obtained if LGN axons were allowed to establish their layer 4 connections up to the point of the onset of segregation before subplate neurons were ablated. Accordingly, in the last set of experiments, kainic acid was injected into the white matter at P18 (two animals) or P20 (two animals), just before the onset of segregation, and about 4 weeks after the first LGN axons have invaded layer 4 (LeVay et al., 1978; Shatz and Luskin, 1986; Ghosh and Shatz, 1992a).

The pattern of geniculocortical projection to cortex was strikingly and surprisingly modified in the animals injected with kainic acid at P18 and P20 (Figs. 13, 14). As shown in the autoradiographs of Figure 13, radioactive label is no longer restricted to layer 4. Instead, label, representing LGN axon terminals, is present throughout the upper layers of the cortical plate as well as within layer 4. Not only is the laminar pattern of LGN innervation of cortex altered, the LGN axons also fail to segregate into ocular dominance columns. This pattern of afferent termination is notably different from that resulting from subplate ablations made during the first postnatal week, in which ocular dominance columns fail to form but the laminar restriction of geniculocortical axons is not disrupted.

An examination of the cytoarchitecture of the cortex in these animals indicates that, as with subplate ablations made during the first postnatal week, there can be disruption of layer 4 (Fig. $14 D$ ). It is remarkable, however, that even in cases where the histology appears normal (Fig. 14B), the pattern of geniculocortical afferents is dramatically altered-radioactive label is clearly present uniformly in layers 2,3 , and 4 . This example particularly suggests that although subplate deletions lead to cellular changes in layer 4 , the observed effects on LGN axon terminals are not due to some gross disruption of the cytoarchitecture of visual cortex.

\section{Discussion}

By ablating subplate neurons early in postnatal life we have examined whether these neurons play a role in the segregation of LGN axons to form ocular dominance columns. We have found that the deletion of subplate neurons during the first postnatal week results in the failure of LGN axons to segregate within layer 4 . Thus, it appears that subplate neurons are somehow involved in the formation of ocular dominance columns. Furthermore, later deletions of subplate neurons perturb the laminar restriction of $\mathrm{LGN}$ axons to layer 4 of cortex. Therefore, subplate neurons may help to direct several aspects of cortical organization during postnatal development, specifically with regard to the development of the geniculocortical projection.

\section{The selectivity of kainic acid lesions}

We have attempted, using various control experiments, to verify that the effects of kainic acid injections into the white matter are limited primarily if not exclusively to subplate neurons. It is apparent from MAP2 immunostaining that about a week after kainic acid injection during the first postnatal week the principal neuronal cell types ablated near the injection site are the subplate neurons. The size of the lesion arca about a weck after injection is quite small, due to the small volume of kainic acid injected and possibly also because our standard addition of fluorescent latex microspheres to the kainic acid solution helped to restrict the size of the lesion. At about 2 weeks after injection, subplate neurons underlying approximately one-third to one-half of visual cortex were often deleted without obvious loss of cortical plate cells.

It is difficult to be absolutely certain that some of the kainic acid did not, in fact, diffuse into the overlying cortical plate, particularly into cortical layer 6 . However, even if this were to occur, the most compelling evidence that the observed changes in visual cortex are not due to a direct effect of kainic acid on cortical layer 4 neurons is that injections of kainic acid directly 

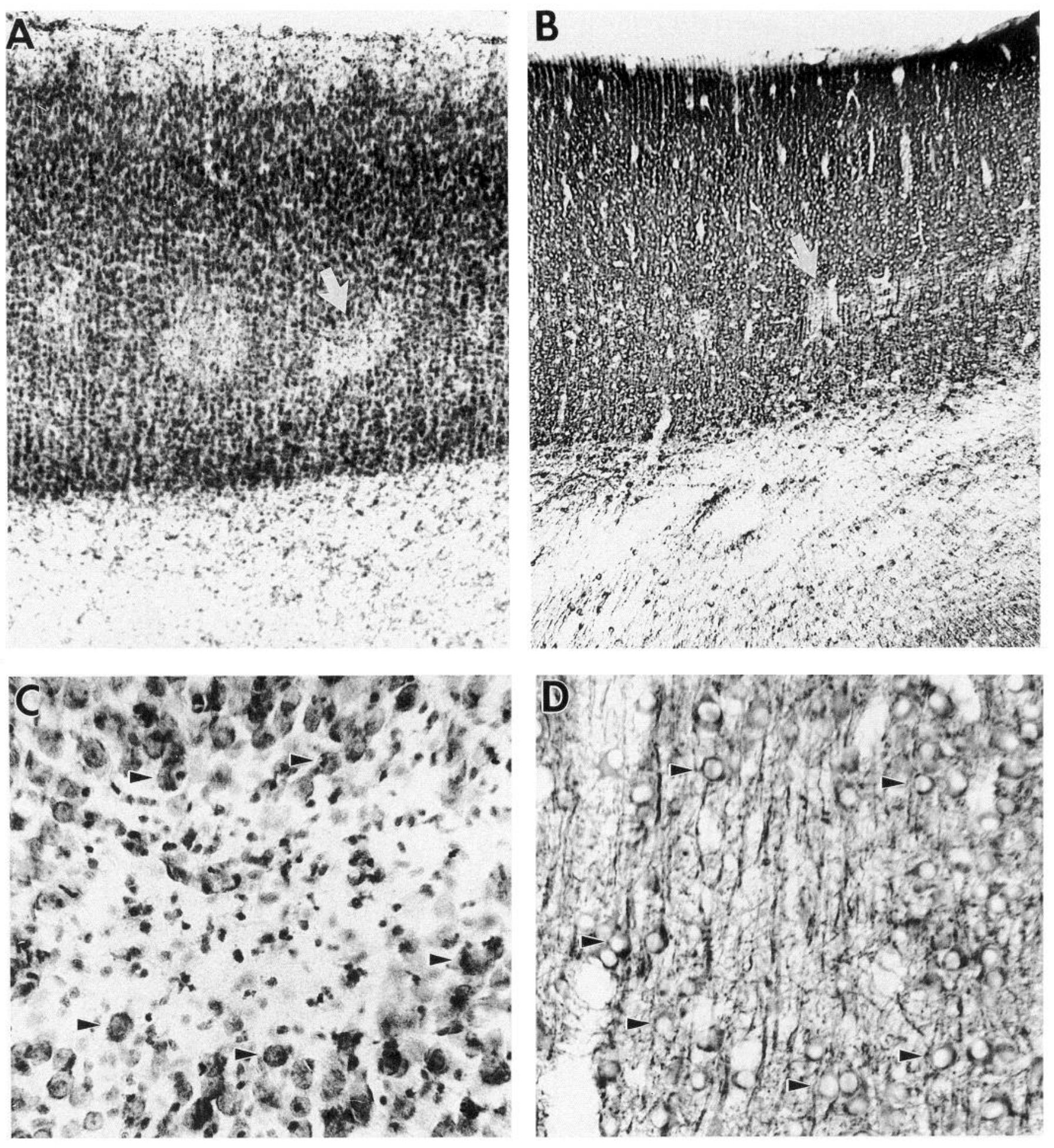

Figure 11. Cytoarchitectural changes in the visual cortex of a P18 animal following white matter kainic acid injections at P4. A and $B$, Adjacent sections stained with cresyl violet and immunoreacted for MAP2 indicate that the first signs of cellular disruption in the cortex are the appearance of zones of reduced staining at the base of layer 4 (arrows). $C$ and $D$, At higher magnification it is evident that these zones contain fewer darkly stained cell bodies (arrowheads), although they contain many smaller cell bodies ( $C$; possibly glia) and MAP2-immunoreactive processes $(D)$ likely to be dendritic branches of surrounding neurons. Scale bar: $A$ and $B, 500 \mu \mathrm{m} ; C$ and $D, 100 \mu \mathrm{m}$.

into layer 4 did not result in any observable changes in cortex, either histologically or on the process of LGN axon segregation. It is perhaps not surprising that kainic injections into layer 4 had no obvious effect on layer 4 neurons in view of the relative immaturity of layer 4 during the first postnatal week. As mentioned in Results, neurons of the cortical plate only gradually acquire susceptibility to excitotoxic damage from kainic acid during development (Coyle et al., 1978, 1981). It is now also 


\section{Ctx}

A

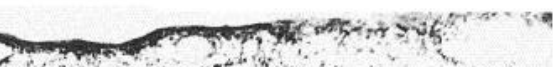

$\therefore \quad s, 4+3$

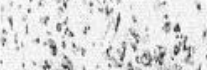

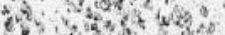

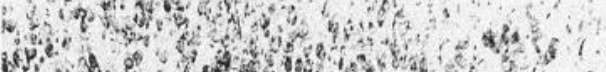

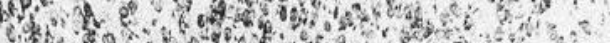

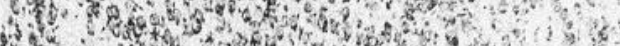

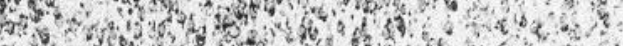

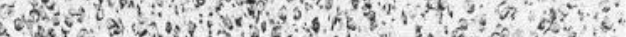

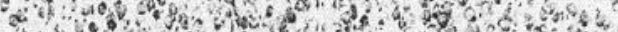

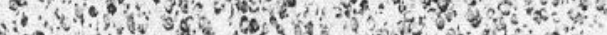
og a

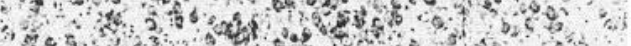

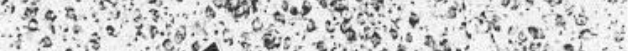

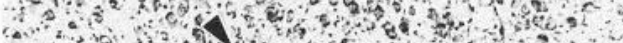

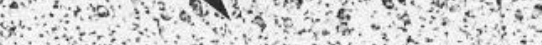

3. 30 b a

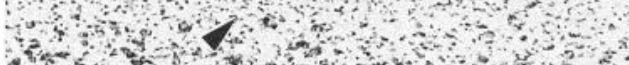

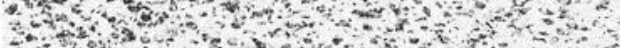

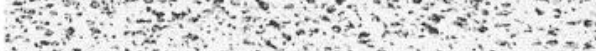

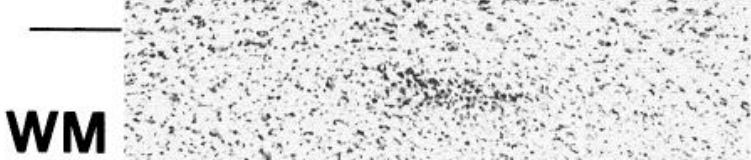

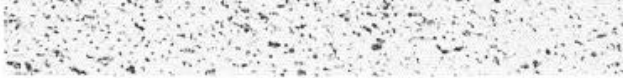

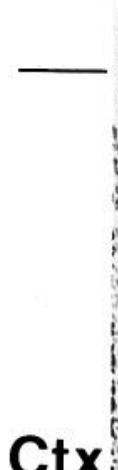

C

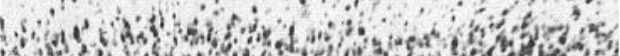

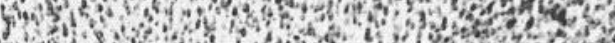

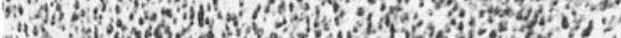

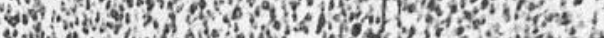

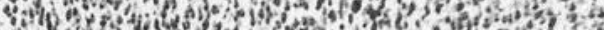
a.t.

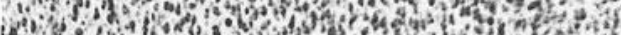

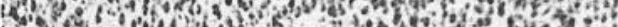

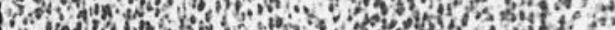
of

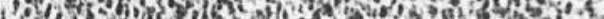

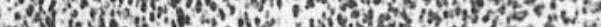

$\mathrm{C}+\mathrm{x}$.

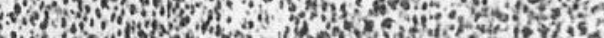

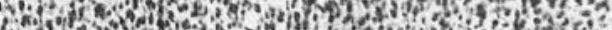
G. 20.

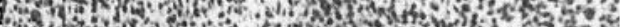
5W 3 wh

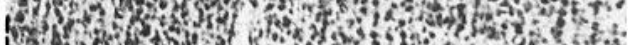

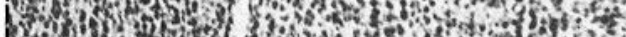

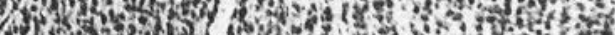

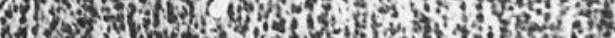

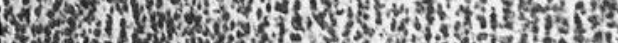

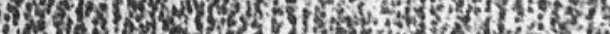

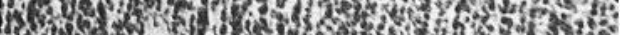

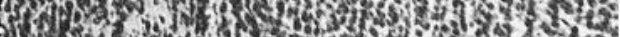

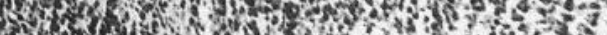

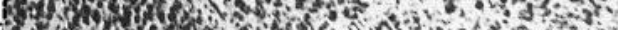

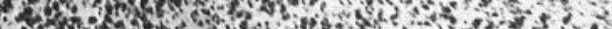

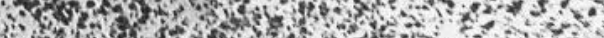

WM

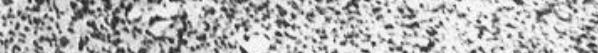

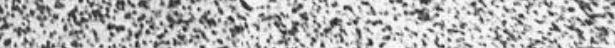

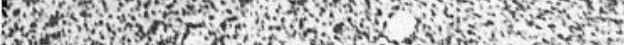

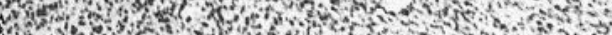

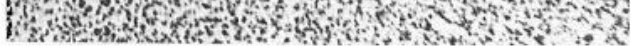
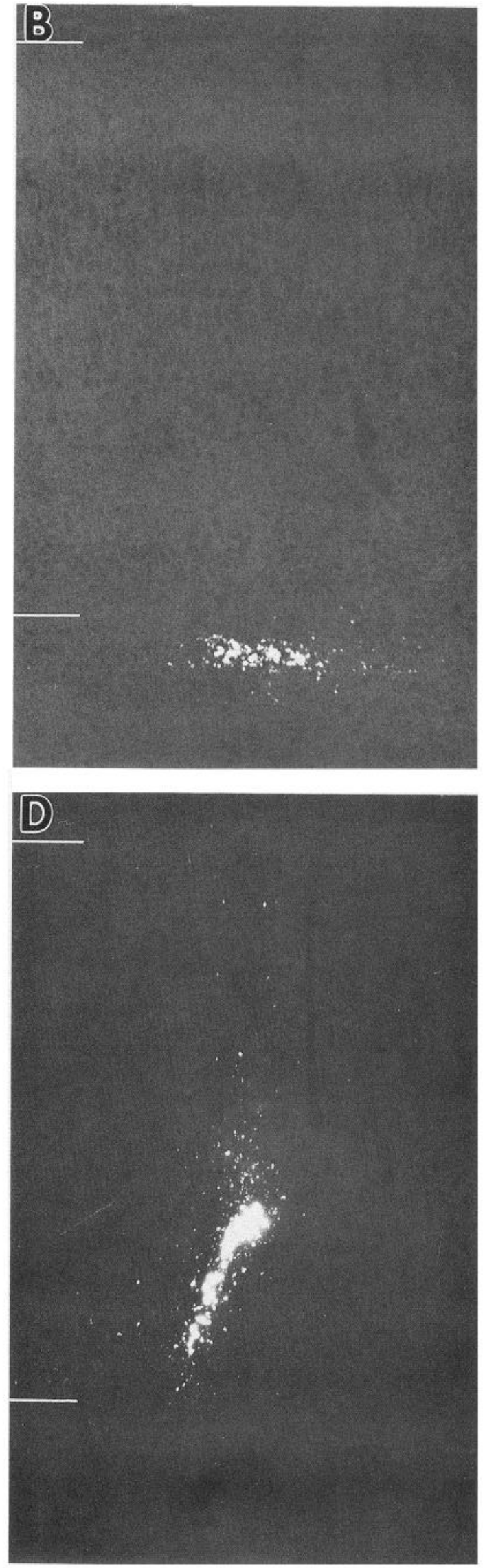
A

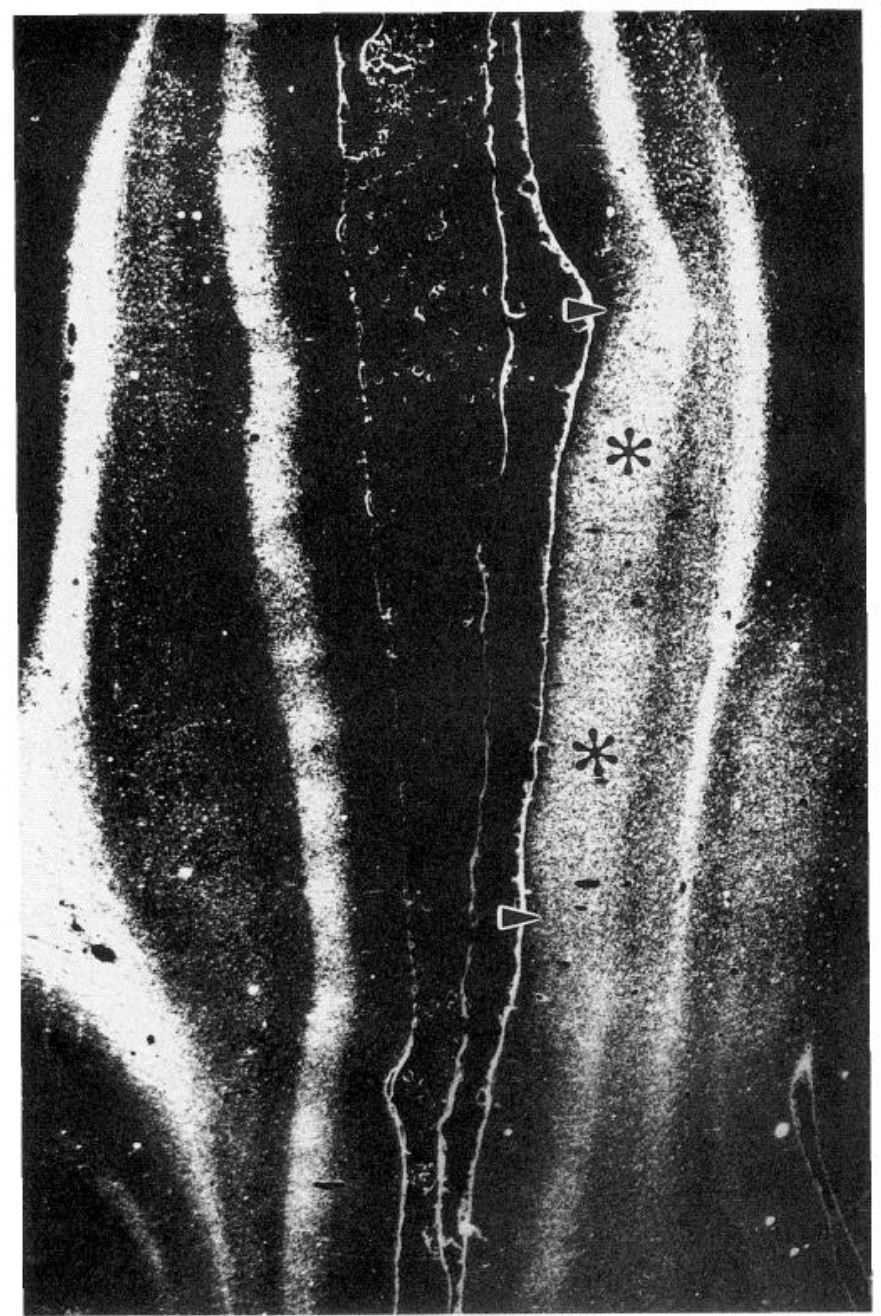

B

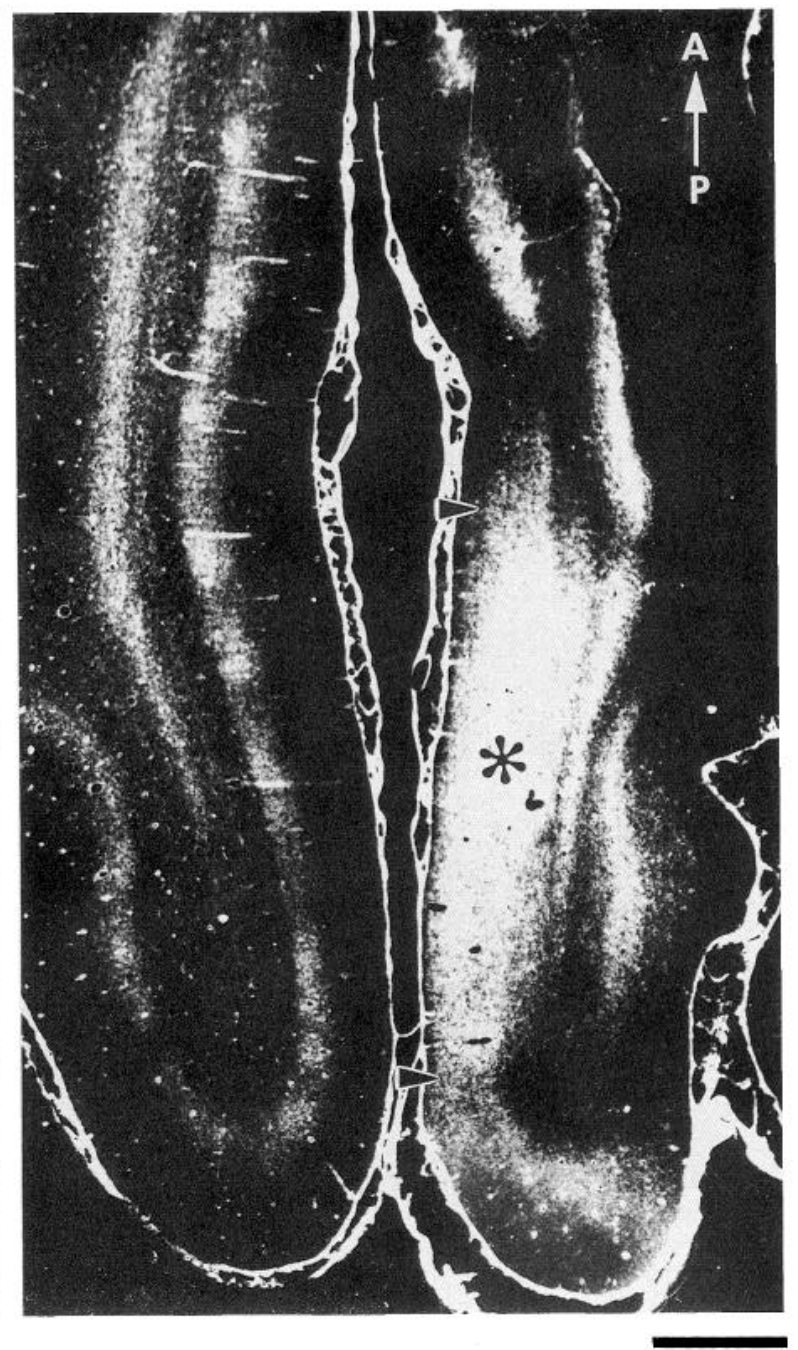

Figure 13. Kainic acid injection into the white matter at P18 prevents the formation of ocular dominance columns and deregulates the laminar restriction of geniculocortical afferents to layer 4 (asterisks). $A$ and $B$, In two separate experiments the pattern of transneuronal labeling was examined at P50 following white matter kainic acid injection at P18. In both cases in the region close to the injection site labeled geniculocortical axons could be seen all the way up to layer 1 (region between arrowheads). Moreover, in both cases the afferents had not segregated into ocular dominance columns. Scale bar, $2 \mathrm{~mm}$.

known from calcium imaging studies at comparable times in the development of rat visual cortex that most cortical neurons initially have functional NMDA responses and only later acquire responsiveness to kainic acid (Yuste and Katz, 1991); in contrast, subplate neurons are much more sensitive to the application of kainic acid than NMDA at similar times in development (Herrmann and Shatz, 1992). In addition, a recent in situ hybridization study of adult monkey visual cortex indicates that, remarkably, the majority of neurons in layers 4 and 6 have very low or undetectable levels of message for glutamate receptor subunits belonging to the kainate receptor subclass (Huntley et al., 1993). If a similar subtype distribution is present in the cat during postnatal development, this observation would also explain the relative resistance of layer 4 (and layer 6) to excitotoxic damage following kainic acid injections either into the subplate or, for that matter, into layer 4 . In sum, these considerations argue strongly that the principal effect of neonatal white matter kainic acid injections on cortical neurons is restricted to subplate.

In experiments where kainic acid injections were made during the third postnatal week, the major cell type ablated is also the subplate neuron, although there may be some loss of deep layer

Figure 12. Effect of white matter kainic acid injections on cortical cytoarchitecture is not due to a direct effect of kainic acid on cortical neurons. $A$ and $B$, Histology of the visual cortex at P55 following white matter kainic acid injection at P5 demonstrates the loss of cells near the base of layer 4 (arrowheads). B, Fluorescent microspheres marking this injection site are restricted to the white matter. $C$ and $D$, Histology of the visual cortex at P55 following a direct cortical injection of kainic acid at P6 reveals no apparent cytoarchitectural changes. The injection site in this case was clearly restricted to the lower half of the cortex and included layer $4(D)$. Ctx, cortex; $W M$, white matter. Scale bar, $250 \mu$ m. 

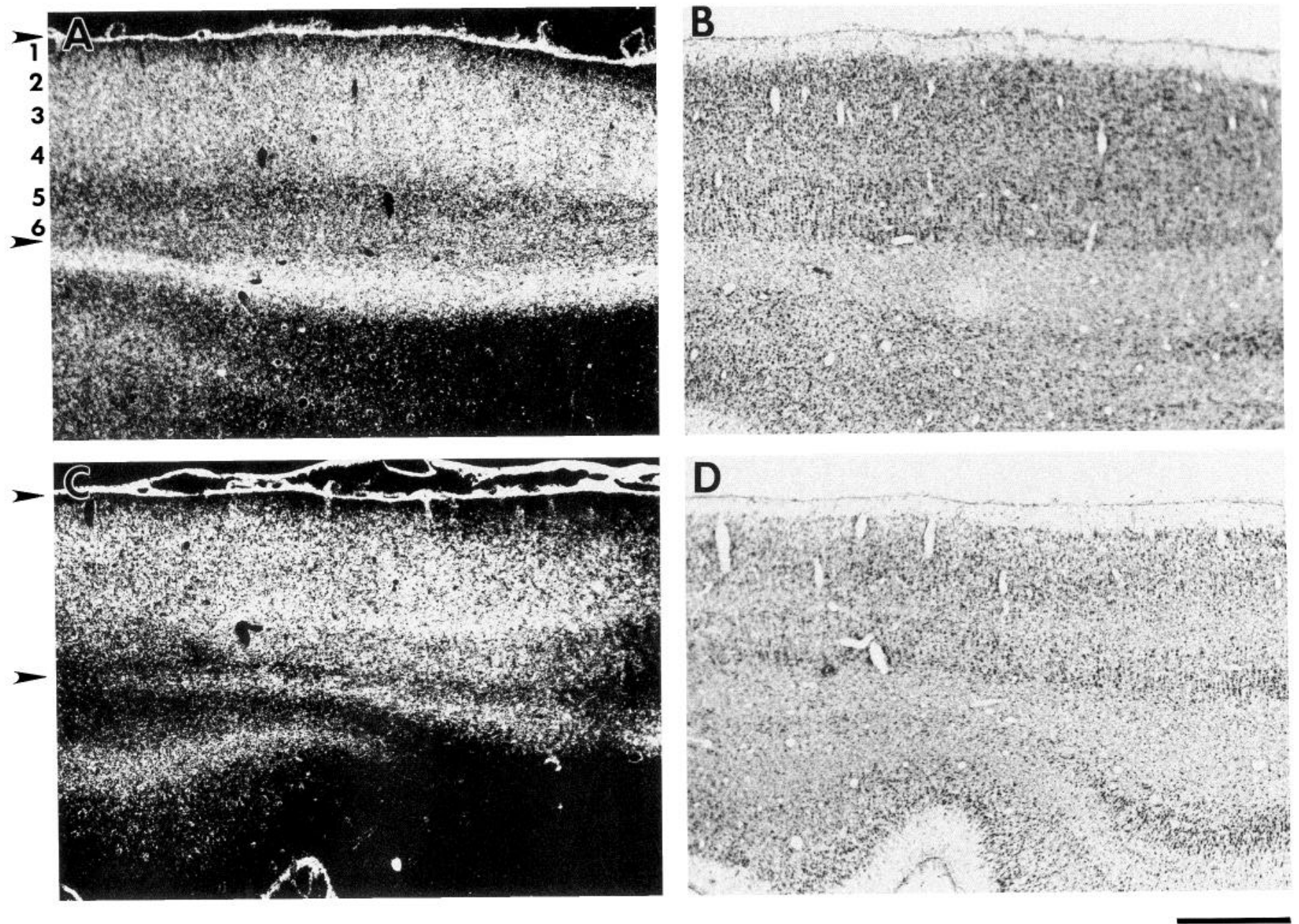

Figure 14. The location of geniculocortical afferents at P50 following kainic acid injection into the white matter at P18 compared to the cortical histology of adjacent sections. $A$ and $C$, Transneuronal label can be seen in layers $2,3,4$, and 6 , indicating that geniculocortical afferents had invaded the superficial layers following kainic acid injections at P18. $B$ and $D$ Cresyl violet staining of sections adjacent to those in $A$ and $C$ reveals varying degrees of cytoarchitectural disruption in these animals. Whereas in $B$ there is no apparent loss of cell staining in the cortex, there appears to be a loss of staining in layer 4 in $D$ similar to that observed following early (P1-P7) kainic acid injections. Scale bar, $1 \mathrm{~mm}$.

6 cells. The interpretation of the late deletion experiments must take this additional possibility into account.

Experiments described here and previously (Ghosh et al., 1990) also indicate that the major glial subtypes, the radial glial cells and astrocytes, are apparently not directly damaged by the kainic acid injections [although we cannot rule out the possibility that kainic acid affects them in some other way, since some glial cells are known to have glutamate receptors (Gallo et al., 1989; Barres et al., 1990)]. Similarly, the majority of LGN axons close to the injection site are unlikely to be affected since these axons are capable of retrogradely transporting fluorescent microspheres coinjected with the kainic acid to their cell bodies within the LGN, where they can be seen labeled well into adulthood. We have shown previously that the genesis and migration of layer 4 neurons, the ultimate targets of LGN axons, are also not affected by kainic acid injections into the subplate at even earlier times in fetal life (Ghosh et al., 1990). Thus, we believe that the major effect of the kainic acid injections into the white matter is on the subplate neurons, which are deleted, making it likely that the changes observed in visual cortex following kainic acid injections are specifically due to the loss of subplate neurons.

\section{The influence of subplate neurons on the segregation of $L G N$} axons

Ever since Hubel and Wiesel described that monocular deprivation during the critical period results in a profound shift in ocular dominance in favor of the open eye (Wiesel and Hubel, 1963; Hubel and Wiesel, 1970), explorations of the mechanisms underlying the process of ocular dominance column formation and susceptibility to abnormal experience have largely shaped our notions of plasticity in the cerebral cortex. The onset of the critical period for the effects of monocular deprivation in the cat was determined to be during the third postnatal week (Hubel and Wiesel, 1970; LeVay et al., 1980). It was subsequently shown that during normal development in the cat, LGN axons representing the two eyes are initially intermixed within cortical layer 4 , and then gradually segregate into ocular dominance columns between the fourth and sixth postnatal weeks (LeVay et al., 1978), consistent with the finding that LGN axon terminals are most susceptible to abnormal visual experience at the beginning of ocular segregation.

The requirement for patterned visual input in order for ocular 
segregation to take place has been tested in a series of experiments where kittens were either dark reared or binocularly lid sutured (Wiesel and Hubel, 1965; Buisseret and Imbert, 1976; LeVay et al., 1980; Swindale, 1981; Kalil, 1982; Swindale and Cynader, 1983; Mower et al., 1985) during the period of ocular segregation. The results of these studies make it evident that a significant degree of segregation can take place in the absence of patterned vision. This is consistent with the observation in the monkey, where ocular segregation begins prenatally (Rakic, 1976) and can continue postnatally in the absence of patterned vision (LeVay et al., 1980). More recently it has been shown that binocular blockade of retinal action potentials by intraocular injections of tetrodotoxin (TTX) prevents the formation of ocular dominance columns within layer 4 (Stryker and Harris, 1986; Antonini and Stryker, 1993), suggesting that spontaneous neural activity in retinal ganglion cells may be sufficient to initiate the segregation of LGN axons and may explain how segregation can occur in the absence of patterned vision. It has also been reported that intracortical infusion of APV (an antagonist of the NMDA receptor) interferes with the shift in ocular dominance that normally results from monocular deprivation, suggesting that synaptic transmission involving NMDA receptors may be involved in cortical plasticity (Bear et al., 1990): Correspondingly, the NMDA receptor-mediated response of cortical neurons also changes during the period of ocular segregation, so that the responses of neurons in cortical layers 4-6 are no longer as sensitive to application of APV, an antagonist of the NMDA receptor (Fox et al., 1989; see also Carmignoto and Vicini, 1992) as segregation proceeds. While many of the above results have allowed insight into the physiological and pharmacological substrates for cortical plasticity, virtually nothing is known about the role of specific cell types in the process of ocular segregation. In the present study we have shown that subplate neurons appear to be required for the segregation of LGN axons within layer 4.

The nature of the interactions between subplate neurons, layer 4 cortical neurons, and LGN axon terminals is not understood, but recent evidence makes it likely that these cellular elements interact functionally during postnatal development. Some of these (hypothetical) interactions are shown diagrammatically in Figure 15. Previous morphological studies in the cat indicate that during the first postnatal week LGN axons are restricted to layer 4 of cortex (LeVay et al., 1978; Shatz and Luskin, 1986; Ghosh and Shatz, 1992a). However, many of these axons still also have collaterals within the subplate (Ghosh and Shatz, 1992a), which may supply the synapses onto subplate neurons known to arise from LGN axons at this time in development (Herrmann et al., 1994). In addition, the subplate neurons themselves send axonal collaterals into the cortex, with branches within layer 4 (Friauf et al., 1990). These relationships suggest that subplate neurons could participate in synaptic interactions involving LGN axons and layer 4 neurons. In fact, current source density recordings in late fetal and neonatal cortical slices suggest that layer 4 cortical neurons can receive functional synaptic inputs from both subplate neurons and LGN axons (Friauf et al., 1990), a suggestion supported by preliminary whole-cell recordings from layer 4 neurons (M. B. Dalva, C. J. Shatz, and L. C. Katz, personal communication). Finally, evidence suggests that layer 4 neurons themselves may extend a transient axon into the subplate (Callaway and Katz, 1992). Such synaptic relationships might function to permit activity-dependent synaptic rearrangements if the coincident activation of both sub-

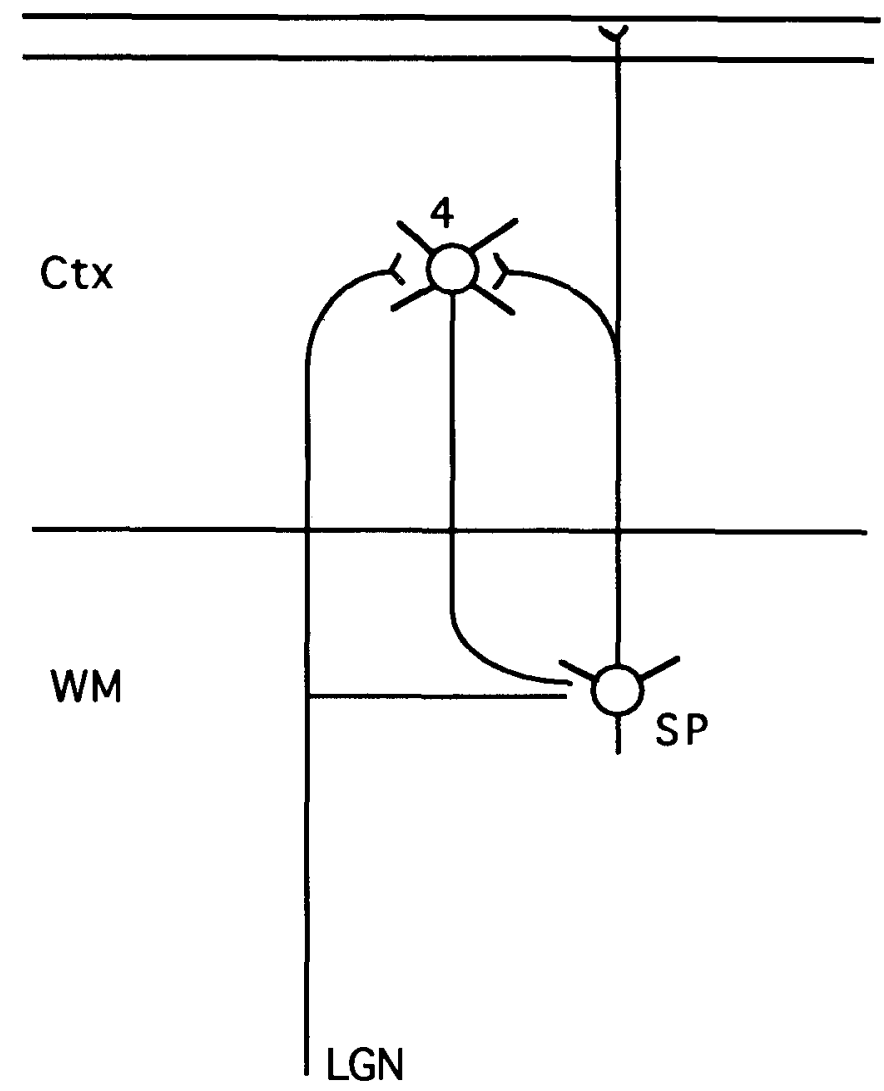

Figure 15. Diagrammatic representation of hypothetical interactions between LGN axons ( $L G N$ ), layer 4 neurons ( 4 ), and subplate ncurons $(S P)$ in the visual cortex before the onset of ocular segregation. LGN axons have branches within both layer 4 of the cortex $(C t x)$ and the white matter ( $W M)$ (Ghosh and Shatz, 1992a), layer 4 neurons have a transient descending projection into the white matter (Callaway and Katz, 1992), and subplate neurons have axonal projections into layers 4 and 1 (Friauf et al., 1990).

plate neurons and LGN axons were required to bring layer 4 neurons to a threshold of depolarization where lasting changes in synaptic strength could occur (Constantine-Paton et al., 1990; Shatz, 1990).

Aside from direct synaptic interactions between subplate neurons and layer 4 neurons, it is also possible that subplate neurons produce diffusible factors that maintain an environment suitable for the segregation of LGN axons. Although the existence of such diffusible factors is entirely speculative at this point, the loss of layer 4 neurons following subplate deletions suggests that subplate neurons might actually provide trophic support for layer 4 neurons during early postnatal development (discussed below in more detail). This line of reasoning raises the possibility that ocular dominance columns fail to form because of the reduced density and loss of layer 4 neurons following subplate ablations, rather than because of direct synaptic interactions between LGN axons, subplate axons, and layer 4 neurons. At this point, it is not possible to unravel the exact sequence of events that ultimately prevents the formation of ocular dominance columns within layer 4 . However, our observations implicate subplate neurons in the process of segregation, especially since cortical plate injections of kainic acid that spare subplate neurons do not prevent column formation.

It is important to note that the autoradiographic evidence 
showing a lack of ocular dominance columns does not permit us to determine how individual LGN axons have been affected by the subplate deletions. For cxample, we cannot distinguish the possibility that LGN axon development was arrested at an immature state corresponding to the time of the kainic acid injection from the alternative that an indiscriminate growth of LGN axons within layer 4 has occurred. Labeling of LGN axons by intracellular dye injection or Phaseolus lectin injections into the LGN of these animals will be necessary to clarify this issue.

\section{Laminar restriction of the geniculocortical projection}

A striking difference between lesions made during the first postnatal week and those made at P18 or P20 is that lesions at older ages result not only in a failure of ocular dominance segregation but, in addition, cause a breakdown of the laminar restriction of LGN axons to layer 4. It is clear from the pattern of autoradiographic labeling that following the later subplate ablations the geniculocortical projection has invaded layers $2 / 3$ even when layer 4 appears not to be significantly disrupted. This is a most unexpected result since, despite many perturbation experiments over the years, the LGN projection into layer 4 has never been found to violate laminar boundaries. For example, in monocularly deprived or TTX-injected animals, where the pattern of ocular dominance is affected, the afferents are always restricted to layer 4 (LeVay et al., 1980; Stryker and Harris, 1986). Similarly, in the mutant Reeler mouse, where the pattern of cortical lamination is essentially inverted, LGN axon terminals remain within layer 4 (Caviness and Frost, 1983). Only in rats that have been treated with an antimitotic agent to destroy layer 2-4 does one find a thalamic projection in layer 5 (Jones et al., 1982), but layer 4 may be missing in our cases too. Since only P18 or P20 lesions, and not the earlier (P2-P8) postnatal lesions, result in this laminar deregulation, it seems likely that changes in cortical organization during the first three postnatal weeks may explain the differential response of LGN axons to subplate ablations made at different ages.

There are indeed significant differences in the connectivity of visual cortex between P7 and P18. Most importantly, by P18, but not at $P 7$, cells of layers $2 / 3$ are postmigratory (Luskin and Shatz, 1985a) and begin to extend axons tangentially within their own layers and radially through layer 4 (Callaway and Katz, 1990). Subplate ablations at P1 8 may perturb the development of the callosal projections into layers $2 / 3$ that occurs at this time-here too, callosal axons wait in the subplate and grow into layer 2/3 beginning about P18 (Innocenti, 1981). If subplate neurons were required for the normal ingrowth of callosal axons into the cortical plate, as they are for LGN neurons during fetal life, then deletion may prevent callosal axons from invading layer $2 / 3$, leaving these layers available for $L G N$ axons to grow into. Finally, by $\mathrm{P} 18$ but not by $\mathrm{P} 7$ the recurrent collateral connections between layer 6 and layer 4 have begun to form (Kat7 and Wiesel, 1987). As mentioned earlier, it is possible that at P1 8 some neurons at the base of layer 6 have also been deleted by the kainic acid, along with subplate neurons. Disruption of the connectivity between layers 6 and 4 could also contribute to the altered behavior of geniculocortical afferents. It is not clear how these changes in cortical circuitry might influence the laminar restriction of LGN axons following subplate ablations, but further investigations of the phenomenon must take into account other cellular interactions in the cortex that may also require subplate neurons.

\section{Effects of subplate ablations on the cytoarchitecture of visual cortex}

In addition to the effect on the segregation of LGN axons, the ablation of subplate neurons results in specific and significant changes in the histology of the cortex. The cellular organization seems especially perturbed at the base of layer 4 . By MAP2 immunocytochemistry it appears that there is a loss of neurons in this region. Several lines of evidence support the interpretation that the effects in layer 4 are secondary consequences of the loss of subplate neurons and not direct effects of the kainic acid injections. First, while the subplate neurons are missing as early as we have looked-4-8 d after a kainic acid injection (Chun and Shatz, 1988a; Ghosh and Shatz, 1993)-the first cellular changes in layer 4 are apparent only 2 weeks following the ablation. Second, while the injections lead to rapid and complete ablation of subplate neurons, the changes in layer 4 are much more gradual. By ${ }^{3} \mathrm{H}$-thymidine labeling layer 4 cells, we know that at 2 weeks after the kainic acid injections most layer 4 neurons are still present. Finally, and perhaps most importantly, direct injections of kainic acid into the cortical plate that spare subplate neurons do not lead to similar cytoarchitectural changes in layer 4 . These observations strongly suggest that the cellular changes in layer 4 are secondary to the loss of subplate neurons.

The question remains, how does the absence of subplate neurons lead to these cytoarchitectural changes? One possibility mentioned above is that layer 4 neurons may derive trophic support from subplate neurons and when the subplate is removed, this leads to an arrest in layer 4 development and, ultimately, to cell death. Another possibility is that loss of subplate neurons prevents LGN axon segregation, which in turn alters the cytoarchitecture of layer 4 (e.g., subplate neurons are not directly involved). At present, it is not possible to distinguish between these two altcrnatives. However, as we learn more about the trophic support of cortical neurons, it may be possible to unravel these interrelated phenomena.

\section{Implications for the critical period in the formation of geniculocortical connections}

Although the existence of a critical period for experience-dependent change in the visual system has been widely documented, little is known about the events that permit changes during the period or bring it to a close. For example, although patterned neural activity is required for ocular segregation, it is not clear why monocular deprivation in the adult does not also result in major anatomical rearrangements of LGN axons within layer 4. One possibility is that fundamental changes occur in the cortex that then greatly limit plasticity beyond a certain point in development.

Unlike previous experiments that somehow directly interfere with the visual experience of the animal to alter the process of segregation during the critical period, the experiments described here prevent ocular segregation without directly affecting visual experience or levels of ascending neural activity in the LGN axons. With regard to the present results, it is important to remember that subplate neurons are a transient feature of the developing cortex. Subplate neurons in cat begin to decline dramatically in number during the first 3 weeks after birth, just prior to the onset of LGN axon segregation, and the majority are gone by the eighth postnatal week (Valverde and FacalValverde, 1988; Chun and Shat7, 1989a), just after LGN axons 
complete the process of eye-specific segregation. Though there is limited relevant evidence, it is noteworthy that subplate neurons have now been described in other mammalian species (Kostovic and Rakic, 1980; Bayer and Altman, 1990), and in the monkey, their time course of disappearance with respect to ocular segregation is analogous to that in the cat (Rakic, 1977; Kostovic and Rakic, 1980, 1990). The fact that, in the monkey, the critical period for the effects of abnormal visual experience in layer 4 normally comes to a close (LeVay et al., 1980) around the same time that subplate neurons have fallen to their adult numbers, coupled with our finding here that an absence of subplate neurons prevents ocular segregation, raises the possibility that subplate neurons are not only necessary for segregation, but their final disappearance may somehow prevent further anatomical rearrangements of LGN axons within layer 4. If so, then subplate neurons may have a major role in the entire developmental history of LGN axons, first by pioneering pathways (McConnell et al., 1989), then by participating in the process of target selection and cortical ingrowth, and finally, by helping to establish an environment conducive for ocular segregation. Since subplate neurons are present throughout neocortex, our studies in the visual system raise the possibility that they may function in similar fashion elsewhere during postnatal periods of synaptic rearrangements within cortical layer 4 .

\section{References}

Allendoerfer KL, Shatz CJ (1993) The subplate, a transient neocortical structure: its role in the development of connections between thalamus and cortex. Annu Rev Neurosci 16:185--218.

Antonini A, Stryker MP (1993) Development of individual geniculocortical arbors in cat striate cortex and effects of binocular impulse blockade. J Neurosci 13:3549-3573.

Barres B, Koroshetz WJ, Swartz KJ, Chun CY, Corey DP (1990) Ion channel expression by white matter glia: the $0-2 \mathrm{~A}$ progenitor cell. Neuron 4:507-524.

Bayer SA, Altman J (1990) Development of layer I and the subplate in the rat neocortex. Exp Neurol 107:48-62.

Bear MF, Kleinschmidt A, Gu QA, Singer W (1990) Disruption of experience-dependent synaptic modifications in striate cortex by infusion of an NMDA receptor antagonist. J Neurosci 10:909-925.

Buisseret P, Imbert P (1976) Visual cortical cells: their developmental properties in normal and dark-reared kittens. J Physiol (Lond) 255: 511-525.

Callaway EM, Katz LC (1990) Emergence and refinement of clustered horizontal connections in cat striate cortex. J Neurosci 10:1134-1153.

Callaway EM, Katz LC (1992) Development of axonal arbors of layer 4 spiny neurons in cat striate cortex. J Neurosci 12:570-582.

Carmignoto G, Vicini S (1992) Activity-dependent decrease in NMDA receptor responses during development of the visual cortex. Science 258:1007-1011.

Caviness VS, Frost DO (1983) Thalamocortical projections in the Reeler mutant mouse. J Comp Neurol 219:182-202.

Chun JJM, Shatz CJ (1988a) Distribution of synaptic vesicle antigens is correlated with the disappearance of a transient synaptic zone in the developing cerebral cortex. Neuron 1:297-310.

Chun JJM, Shatz CJ (1988b) A fibronectin-like molecule is present within the developing cat cerebral cortex and is correlated with subplate neurons. J Cell Biol 106:857-872.

Chun JJM, Shatz CJ (1989a) The earliest-generated neurons of the cat cerebral cortex: characterization by MAP2 and neurotransmitter immunohistochemistry during fetal life. J Neurosci 9:1648-1667.

Chun JJM, Shatz CJ (1989b) Interstitial cells of the adult neocortical white matter are the remnant of the early generated subplate neuron population. J Comp Neurol 282:555-569.

Coyle JT, Molliver ME, Kuhar MJ (1978) In situ injection of kainic acid: a new method for selectivity lesioning neuronal cell bodies while sparing axons of passage. J Comp Neurol 180:301-324

Coyle JT, Bird SJ, Evans RH, Gulley RI, Nadler JV, Nicklas WJ, Olney JW (1981) Excitatory amino acid neurotoxins: selectivity, specificity and mechanisms of action. Neurosci Res Prog Bull 19:331-427.
Fox K, Sato H, Daw N (1989) The location and function of NMDA receptors in cat and kitten visual cortex. J Neurosci 9:2443-2454.

Friauf E, McConnell SK, Shatz CJ (1990) Functional synaptic circuits in the subplate during fetal and early postnatal development of cat visual cortex. J Neurosci 10:2601-2613.

Gallo V, Giovannini C, Suergin R, Levi G (1989) Expression of excitatory amino acid receptors by cerebellar cells of the type- 2 astrocyte cell lineage. J Neurochem 52:1-9.

Ghosh A, Shatz CJ (1992a) Pathfinding and target selection by developing geniculocortical axons. J Neurosci 12:39-55.

Ghosh A, Shatz CJ (1992b) Involvement of subplate neurons in the formation of ocular dominance columns. Science 255:1441-1443.

Ghosh A, Shatz CJ (1993) A role for subplate neurons in the patterning of connections from thalamus to neocortex. Development 117:10311047.

Ghosh A, Antonini A, McConnell SK, Shatz CJ (1990) Requirement for subplate neurons in the formation of thalamocortical connections. Nature 347:179-181.

Herrmann K, Shatz CJ (1992) Glutamate-induced calcium responses of developing subplate cells. Soc Neurosci Abstr 18:924.

Herrmann K, Antonini A, Shatz CJ (1994) Ultrastructural evidence for synaptic interactions between thalamocortical axons and subplate neurons. Eur J Neurosci, in press.

Hubel DH, Wiesel TN (1970) The period of susceptibility to the physiological effects of unilateral eye closure in kittens. J Physiol (Lond) 206:419-436.

Hubel DH, Wiesel IN (19\%) Functional architecture of macaque monkey visual cortex. Proc R Soc London [Biol] 198:1-59.

Huntley GW, Rogers SW, Moran T, Janssen W, Archin N, Vickers JC, Cauley K, Heinemann SF, Morrison JH (1993) Selective distribution of kainate receptor subunit immunoreactivity in monkey neocortex revealed by a monoclonal antibody that recognizes glutamate receptor subunits GluR5/6/7. J Neurosci 13:2965-2981.

Innocenti C (1981) Growth and reshaping of axons in the establishment of visual callosal connections. Science 212:824-827.

Jones EG, Valentino KL, Fleshman JW Jr (1982) Adjustment of connectivity in rat neocortex after prenatal destruction of precursor cells of layers II-IV. Dev Brain Res 2:425-431.

Kostovic I, Rakic P (1980) Cytology and time of origin of interstitial neurons in the white matter in infant and adult human and monkey telencephalon. J Neurocytol 9:219-242.

Kostovic I, Rakic P (1990) Developmental history of the transient subplate zone in the visual and somatosensory cortex of the macaque monkey and human brain. J Comp Neurol 297:441-470.

LeVay S, Stryker MP, Shatz CJ (1978) Ocular dominance columns and their development in layer IV of the cat's visual cortex: a quantitative study. J Comp Neurol 179:223-224.

LeVay S, Wiesel TN, Hubel DH (1980) The development of ocular dominance columns in normal and visually deprived monkeys. $\mathbf{J}$ Comp Neurol 191:1-51.

Levitt P, Rakic P (1980) Immunoperoxidase localization of glial fibrillary acidic protein in radial glial cells and astrocytes of the developing rhesus monkey brain. J Comp Neurol 193:815-840.

Luskin MB, Shatz CJ (1985a) Studies of the earliest-generated cells of the cat's visual cortex: cogeneration of subplate and marginal zones. J Neurosci 5:1062-1075.

Luskin MB, Shatz CJ (1985b) Neurogenesis of the cat's primary visual cortex. J Comp Neurol 242:611-631.

Matus A, Bernhardt R, Jones HJ (1981) High molecular weight microtubule-associated proteins are preferentially associated with dendritic microtubules in brain. Proc Natl Acad Sci USA 787:3010-3014.

McConnell SK, Ghosh A, Shatz CJ (1989) Subplate neurons pioneer the first axon pathway from the cerebral cortex. Science 245:978982.

Mower GD, Caplan CJ, Christen WG, Duffy FH (1985) Dark-rearing prolongs physiological but not anatomical plasticity of the cat visual cortex. J Comp Neurol 235:448-466.

Rakic P (1976) Prenatal genesis of connections subserving ocular dominance in the rhesus monkey. Nature 261:467-471.

Rakic P (1977) Prenatal development of the visual system in the rhesus monkey. Philos Trans R Soc Lond [Biol] 278:245-260.

Shatz CJ (1990) Impulse activity and the patterning of connections during CNS development. Neuron 5:745-756.

Shatz CJ, Luskin MB (1986) Relationship between the geniculocortical afferents and their cortical target cells during development of the cat's primary visual cortex. J Neurosci 6:3655-3668. 
Shatz CJ, Stryker MP (1978) Ocular dominance in layer IV of the cat's visual cortex and the effects of monocular deprivation. J Physiol (Lond) 281:267-283.

Shatz CJ, Lindstrom SH, Wiesel TN (1977) The distribution of afferents representing the right and left eyes in the cat's visual cortex. Brain Res 131:103-116.

Shatz CJ, Ghosh A, McConnell SK, Allendoerfer KL, FriaufE, Antonini A (1991) Pioneer neurons and target selection in cerebral cortical development. Cold Spring Harbor Symp Quant Biol 55:469-480.

Stryker MP, Harris WA (1986) Binocular impulse blockade prevents the formation of ocular dominance columns in cat visual cortex. $\mathbf{J}$ Neurosci 6:2117-2133.

Swindale NV (1981) Absence of ocular dominance patches in darkreared cats. Nature 290:332-333.

Swindale NV, Cynader MS (1983) Physiolugical segregation of geniculate afferents in the visual cortex of dark-reared cats. Soc Neurosci Abstr 9:24.
Valverde F, Facal-Valverde MV (1988) Postnatal development of interstitial (subplate) cells in the white matter of the temporal cortex of kittens: a correlated Golgi and electron microscopic study. J Comp Neurol 269:168-192.

Wiesel TN, Hubel DH (1963) Single-cell responses in striate cortex of kittens deprived of vision in one eye. J Neurophysiol 26:10031017.

Wiesel TN, Hubel DH (1965) Comparison of the effects of unilateral and bilateral closure on cortical unit responses in kittens. J Neurophysiol 28:1029-1040.

Wiesel TN, Hubel DH, Lam DMK (1974) Autoradiographic demonstration of ocular-dominance columns in the monkey striate cortex by means of transneural transport. Brain Res 79:273-279.

Yuste R, Katz LC (1991) Control of postsynaptic $\mathrm{Ca}^{2+}$ influx in developing neocortex by excitatory and inhibitory neurotransmitters. Neuron 6:333-334. 